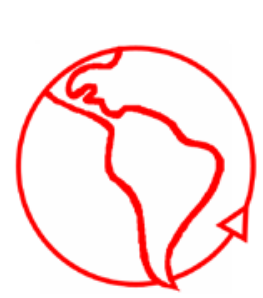

\title{
Sociología de la intervención: orientación sistémica contextual
}

\author{
Sociology of Intervention: Contextual Systemic Steering
}

\section{Aldo Mascareño}

Universidad Adolfo Ibáñez, Chile

\section{Resumen}

La diferenciación funcional de la sociedad moderna indica la autonomía y clausura operativa de sistemas sociales. Esta condición es compensada por mecanismos de acoplamiento estructural entre sistemas que permiten una coordinación social relativamente integrada. No obstante, ni conflictos, intervenciones o desdiferenciaciones sistémicas, como tampoco rendimientos sistémicos que afecten el entorno social como el riesgo ecológico o la pobreza son inusuales en la sociedad moderna. La pregunta de este artículo es bajo qué condiciones es posible la regulación sistémica para abrir vías de solución a estos problemas sin que ello implique una intervención autoritativa de sistemas sociales. Se explican e ilustran los principios de una intervención sistémica contextual como coordinación pragmática de intransparencias. La función de esta estrategia consiste en incrementar la contingencia del sistema a regular con ofertas comunicativas en el lenguaje del sistema; su prestación reside en el tratamiento social de los problemas diagnosticados.

\begin{abstract}
Functional differentiation of modern society entails autonomy and operational closure of social systems. That condition can be compensated by mechanisms of structural coupling between systems which aim to a relatively integrated societal coordination. Nonetheless, neither systemic conflicts, interventions, dedifferentiations, nor systemic outcomes that affect the social environment - such as ecological risks or poverty- are unusual events in modern society. This article raises the question about the conditions under which a systemic steering of these problems is possible without exercising an authoritative intervention in social systems. The principle of a contextual systemic intervention as a pragmatic coordination of intransparencies are explained and illustrated. The function of this strategy consists in increasing the contingency of the addressee with communicative offers in the language of the system; its performance aims to deal with the diagnosed problems.
\end{abstract}

Palabras Clave: Intervención; contingencia; clausura operativa; apertura cognitiva; orientación sistémica contextual

Keywords: Intervention; contingency; operational closure; cognitive openness; contextual systemic steering 
A Leonor Mascareño Moldenhauer

\section{Introducción 1}

Las páginas que siguen arrancan de la tesis que en el contexto de la sociedad moderna, la intervención social solo es posible como orientación sistémica contextual, es decir, como una invitación e incentivo a la autorregulación de sistemas (sociales y psíquicos) autónomos, operativamente clausurados y cognitivamente abiertos a su entorno sobre la base de sus propias distinciones. En tanto las fantasías planificadoras sucumbieron ante la evidencia de que el futuro nunca adviene como se prevé y que obligarlo genera más externalidades negativas que resultados esperados, alguna esperanza para enfrentar el structural drift de la sociedad moderna puede sostenerse aún sobre la base de una teoría de la orientación contextual de sistemas autónomos diferenciados.

Mediante ella se busca construir una estrategia pragmática de coordinación de sistemas autónomos intransparentes y opacos uno frente a otro dadas sus condiciones de clausura operativa. El carácter pragmático de la coordinación se hace necesario ante los distintos lenguajes de cada sistema, las diversas expectativas normativas de los actores acoplados a ellos y la evidente ausencia de un centro coordinador de la complejidad social alcanzada. Sin acuerdo fundante, queda la coordinación pragmática de rendimientos sistémicos que solo esperan posibilidades operativas de continuar funcionando.

Condición de posibilidad de esa coordinación es la apertura cognitiva hacia el entorno de cada sistema. Ella constituye la forma de observación del sistema sobre la base de su clausura operativa, es decir, constituye su modo propio e irrepetible de reconocer el mundo. En tal sentido, el desafío de la orientación sistémica contextual es captar las especificidades de cada sistema para, en su lenguaje, ofrecer las distinciones que la intervención busca introducir: mayor sensibilidad ecológica en la empresa, mayor sentido ético en los medios de comunicación, mayores condiciones de equidad en organizaciones, más conciencia solidaria en la esfera pública. Cuando ello se logra, es el propio sistema objeto de la intervención el que reconoce la propiedad y conveniencia de adoptar la distinción ofrecida y de comenzar a operar en el sentido que la intervención lo propuso. No hay coacción ni compulsión al consenso en la orientación sistémica contextual. Su prueba de efectividad es el autosometimiento del sistema a las condiciones que la intervención (sistémica contextual) dispone; autosometimiento que tiene lugar porque al sistema le parece que aquello que se le ofrece favorece las condiciones de su propia clausura operativa, como los troyanos cuando permiten que el caballo griego entre a su ciudad.

Para presentar este modelo con algún detalle, inicio con una aclaración conceptual de lo que llamo orientación sistémica contextual (1) para luego dar cuenta de sus problemas y posibilidades en el contexto de una sociedad moderna funcionalmente diferenciada (2) entendida bajo el concepto de comunicación como instancia constitutiva de la operación de sistemas sociales y, con ello, de los procesos de intervención (3). Posteriormente, son propuestas las premisas de una orientación sistémica contextual (4) y sobre esa base se despliega el modelo de la orientación sistémica contextual, su metódica no invasiva de intervención (5). Finaliza el texto con una evaluación de las consecuencias éticas de la orientación contextual (6).

\section{El horizonte de la orientación sistémica contextual}

A lo largo de estas páginas sostengo mi exposición en tres conceptos cuyo sentido ahora aclaro. Se trata de los conceptos de orientación, coordinación e intervención. Orientación

\footnotetext{
${ }^{1}$ Agradezco a Alvaro Mascareño la recopilación de algunos de los materiales contenidos en este texto. Este artículo es parte de las actividades de investigación de los proyectos Fondecyt 1110437 y 1110428.
} 
sistémica contextual es el término adoptado para traducir la categoría alemana de systemische Kontextsteuerung. Helmut Willke, iniciador de esta perspectiva, define la orientación contextual del modo siguiente:

En lo esencial, orientación contextual significa la orientación reflexiva y descentralizada de las condiciones contextuales de todos los sistemas y la autoorientación autorreferencial de cada sistema en particular. Orientación descentralizada de las condiciones contextuales significa que una medida mínima de orientación común o 'visión de mundo' es inevitable, pero ese contexto común no puede ser más preestablecido por una unidad central o por una cima de la sociedad. Las condiciones contextuales deben más bien estar constituidas por el discurso de las unidades autónomas en el cual el consenso sobre el fundamento de un disenso basal es posible pero improbable. (Willke 1993: 58)

Orientación contextual es, en este sentido, un marco de referencia para la coordinación de la sociedad; intervención es una estrategia que operativiza ese marco, y coordinación es el resultado de esas estrategias para una observación de segundo orden que observa relaciones entre sistemas. El carácter contextual de la orientación y de la intervención es una precondición sistémica de la aplicación de los mismos: la clausura solo posibilita actuar por el contexto. Puesto de otro modo: mientras que la orientación hace referencia a un marco general de condiciones a través de las cuales los sistemas sociales pueden establecer coordinaciones (o también producir descoordinaciones), la intervención se apoya en un énfasis estratégico que intenta responder a la pregunta por las formas concretas de su operar. Es decir, la orientación se realiza por medio de intervenciones, con lo que para una determinada relación entre sistemas podrán existir formas paralelas de intervención vinculadas por el marco de condiciones que sugiere la orientación, es decir, la intervención logra la gestión de las consecuencias a partir del estado general de una estrategia de orientación social.

La orientación e intervención contextual es la propuesta de quien orienta hacia la coordinación pragmática de intransparencias. Antes de diseñarla, éste ha desarrollado procesos de auto y hetero- observación, de auto y heterodescripción, de autodiferenciación y autoproducción de las distinciones que la intervención introducirá al contexto en el cual opera, y es a partir de ese contexto que la relación entre orientación e intervención puede entenderse de manera más clara. La intervención es la forma corporalizada y temporalizada del marco de condiciones de orientación y, como tal, tiene la capacidad de conocer mejor que nadie las características del contexto de intervención y de retroalimentar aquel marco de condiciones con el procesamiento de la información que observa. Sin este rasgo, la orientación perdería heterorreferencia ante las consecuencias de sus propias acciones, además su flexibilidad para responder a ellas se vería notablemente restringida.

En el sentido expuesto, los propios alcances del concepto de intervención deben ser redefinidos. En rigor, en un contexto de sistemas sociales operativamente clausurados ninguna intervención es realmente posible. La clausura es la atmósfera del mundo sistémico: todo lo que busque llegar a su superficie debe pasar por su filtro. En ocasiones, las consecuencias de meteoritos intrusos podrán ser catastróficas y provocar radicales cambios de era; en otras, aquellos se disolverán en románticas luces nocturnas con consecuencias solo para los enamorados. Pero nunca, bajo ningún punto de vista, lo que viene desde el exterior será recibido en su versión original sobre la superficie del planeta. Asimismo, la clausura operativa, la recursiva capacidad estructurante de las comunicaciones sistémicas desarrolladas en base a un medio simbólicamente generalizado de comunicación, dificultan cualquier cambio substancial. La comunicación es incluso más radical que la naturaleza, pues en tanto la atmósfera transforma los cuerpos extraños, la comunicación sistémica ignora, o a lo más, se irrita ante lo que a ella le parece relevante, y cuando esta improbable probabilidad se probabiliza, entonces además comprende bajo los parámetros que solo ella puede 
comprender y que únicamente por una infinita casualidad podrán ser similares a los de un intruso que busca resonancia en mundos ajenos.

De ahí la necesidad de la contextualidad en las estrategias de intervención. Al contexto del sistema es posible acceder por medio de distinciones sistémicamente relevantes; a su interioridad, solo bajo las propias vestimentas del sistema afectado. Siendo así, una teoría de la orientación contextual no puede entender la intervención como una estrategia que cambia estados de cosas en el sistema al modo que un cirujano implanta un by-pass o extirpa un tumor. La intervención es principalmente estratégica y temática, pero nunca efecto de una causa, nunca directo resultado del exterior, pues los resultados dependen siempre - no en última, sino que en toda instancia- del sistema. Será él quien reconozca comunicaciones relevantes, él quien la procese, él quien genere resonancia y él quien extraiga de todo ello las consecuencias necesarias, en caso que lo haga. Por esto, la intervención es reconocible bajo el marco de la orientación, y más aún, como auto- orientación, como aquello que nos indica la fuerza de una guía y a la vez la contingencia de una selección, la ironía de pretender provocar un cambio que se sabe depende únicamente del que cambia.

\section{Diferenciación funcional como contexto de la intervención contextual}

En la actualidad, uno de los dilemas fundamentales que las ciencias sociales han sido llamadas a resolver, está en la tematización de la complejidad social que caracteriza a la sociedad moderna. La creciente autonomización de las diversas esferas de lo social que pugnan por su desvinculación respecto de los espacios a los que antes estuvieron sujetas $-\mathrm{y}$ que incluso cuestionan la propia concepción de la sociedad como totalidad- constituye un nuevo escenario para la praxis social y un nuevo desafío para lograr comprenderla y operar dentro de ella.

Cada vez menos, la sociedad, por medio de sus diversos mecanismos de auto- observación, logra describirse a sí misma unitariamente sin tener que renunciar al reconocimiento de su alta contingencia y alteridad. Las distintas esferas de la sociedad se independizan y, en tal proceso, constituyen modos de funcionamiento propios que las distinguen y les dan identidad. Nada de lo que ellas realicen puede escapar a su forma de auto- y heterointerpretación. Por ello, es cada vez menos lo que tienen en común y es cada vez más grande la distancia que media entre ellas. La producción de una sociedad diferenciada es el resultado final de esta clausura en las formas operativas de los sistemas de la sociedad; la intransparencia, es decir, la opacidad del funcionamiento sistémico de cada sistema frente a otro, es su consecuencia más inmediata y el primer problema que la sociedad debe resolver para autodescribirse como tal.

Sin embargo, la sociedad en general funciona. Es decir, aun cuando los sistemas sociales operan en ámbitos de sentido específicos, la construcción de una imagen de sociedad produce una coordinación de intransparencias, una coordinación de las opacidades, de las clausuras operativas de sistemas diferenciados. En la sociedad diferenciada esta coordinación debe superar una condición paradojal: sus sistemas operan autónomamente, pero puesto que coexisten temporalmente, las consecuencias de su autopoiesis pueden producir la intervención de operaciones de otros sistemas y, con ello, el quiebre de su autonomía. Es decir, las dificultades aparecen en los límites sistémicos cuando los rendimientos de la autonomía funcional de uno se cruzan con los rendimientos de la autonomía de otro sobre un mismo escenario de operaciones. En esos espacios, en los que se juega la continuidad o transformación de la sociedad, es donde los mecanismos de orientación sistémica contextual operan, sea para producir la coordinación de lo diferenciado o para transformar los rasgos semánticos o estructurales compartidos.

Este hecho es el principal desafío de la sociedad moderna contemporánea, pues a diferencia de su período temprano o aun clásico, la sociedad responde hoy con mayor dificultad a los ímpetus apasionados de un director de orquesta. $\mathrm{Ni}$ el primado político de 
Hegel, ni el económico de Marx o el racional de Weber parecen tener en la actualidad la trascendencia que estos autores mostraron en sus respectivos diagnósticos. En el concierto de la sociedad los instrumentos interpretan sus propias partituras solo en el timbre, volumen y tono en que saben hacerlo, y no es parte de sus preocupaciones inmediatas coordinar un funcionamiento acoplado, o dejar de hacerlo. Solo la relación con otros, el encuentro entre ego y alter, la doble contingencia invita a pensar en la limitación de las posibilidades bajo las cuales un sistema desarrolla su capacidad reflexiva.

Si este es un desafío para los sistemas de la sociedad, es también un desafío para las disciplinas que se encargan de observarla y trabajar en ella. Así, el tema que con esto se abre a la observación sociológica es el de las formas de orientación e intervención de la complejidad social diferenciada. El dilema es el siguiente: si por funcionar de modo autónomo los sistemas pueden interferirse mutuamente, la pregunta sociológica deberá estar enfocada en las formas que adopta esa interferencia, en las consecuencias que tiene para los afectados y en la posibilidad de orientar la autonomía sistémica sin destruirla. Disciplinas como la economía o el derecho ya han desarrollado una reflexión más o menos estructurada sobre este tema bajo el concepto de regulación, reflexión que especialmente en el primero de los casos se ha constituido en la base para el diseño de estrategias empíricas de orientación del sistema económico. Para el derecho en cambio, el tema regulativo es parte de sus propias operaciones basales, es decir, es parte de lo que el sistema jurídico no puede dejar de hacer en su funcionamiento. Salvo por los esfuerzos analíticos de la filosofía del derecho - que más bien deben considerarse dentro del sistema ciencia y de la discusión académica - las consecuencias regulativas del sistema jurídico tratan acerca de la gestión empírica de las interacciones entre personas o de las comunicaciones en los sistemas de la sociedad - donde se incluye el propio sistema jurídico- y no tanto del meta- análisis acerca de la forma que adopta tal orientación.

En el discurso sociológico, en tanto, la intervención y la orientación social no han sido espacios de reflexión privilegiados y menos han logrado la producción de estrategias empíricas que expresen en la contingencia social la forma de sus presupuestos teóricos. Probablemente los esfuerzos de Touraine hayan estado en el pasado tenuemente orientados en esta dirección, pero el nivel particularista en que desarrolla su reflexión unido a su observación desde la teoría de la acción, le negaron el grado de abstracción necesario para pensar el problema en términos de sistemas.

La teoría de sistemas sociales ha comenzado a desarrollar importantes avances en esta materia. Aunque primarias, estas aproximaciones logran situar el problema en el contexto de una sociedad diferenciada cuyos diversos ámbitos tienen una especial predilección por funcionar autónomamente. Lo que lleva a pensar en categorías como invitación a la autoorientación de H. Willke (1987) o capacidad de auto-orientación de G. Teubner (1993), es que cualquier proceso empírico de orientación social debe tener claro que su éxito dependerá de la incorporación que el sistema a regular haga de las distinciones propuestas. Es decir, el éxito final del dilema regulativo no está en el regulador o en su estrategia, sino en la incorporación que el propio sistema que es transformado hace de la oferta de regulación.

Una visión de este tipo puede aproximarse a la sociedad bajo dos fórmulas. La primera de ellas podrá actuar en el momento en que la reproducción autopoiética de las operaciones sistémicas se traduce consecuencias inestabilizantes para el entorno. Situaciones como el daño ecológico, la politización de la justicia, la juridificación de la familia aportan antecedentes al respecto. La intransparencia y opacidad de cada lenguaje sistémico frente a otro dificulta su coordinación y obstaculiza su referencia a los resultados de sus rendimientos: la economía produce independientemente de sus efectos en el entorno naturaleza, las instituciones jurídicas se ven penetradas por problemas de poder con origen en un sistema político que muestra pretensiones universalizantes, o por dinero, caso en de corrupción del poder judicial o corrupción de la política. La tarea de la orientación contextual 
bajo estas condiciones puede ser entendida como una gramática transformacional (Willke 1987) que traduce al sistema las consecuencias que tiene para el entorno sus operaciones autónomas clausuradas y que producto de esa clausura los propios sistemas no logran observar.

Un segundo tipo de escenario al cual deben enfrentarse los procesos de orientación es el que existe en espacios sociales que aun cuando muestran una creciente complejización que reclama diferenciación, mantienen en sus estructuras tendencias desdiferenciadoras que dificultan la autonomía de sus operaciones. Lo anterior tiene una especial actualidad en contextos de diferenciación funcional como los que se despliegan en ciertas regiones de Latinoamérica. Desde nuestro punto de observación, América Latina supone la coexistencia de procesos de diferenciación funcional que corren paralelos a la mantención de estructuras plurifuncionales que presionan por una desdiferenciación (Mascareño 2010a, 2010b, 2011a). Es decir, mientras en ciertos sectores la sociedad autonomiza sus ámbitos operativos, en otros la unidad se mantiene (por ejemplo, entre espacios económicos y políticos, entre socialización y moral pública) y reclama su derecho a integrar la totalidad desdiferenciando lo diferenciado. ${ }^{2}$ Más aún, puesto que la funcionalización es un proceso en marcha, sectores que se describen bajo una alta autonomía como la política, la economía o el sistema jurídico, pueden manifestar desdiferenciaciones integrativas de sus estructuras, limitando la independencia operativa de cada ámbito.

En un espacio de este tipo, las estrategias de orientación social no solo tienen que lidiar con la coordinación de las intransparencias entre sistemas, sino además con el ímpetu hegemónico de ellos por controlar su entorno y con la pretensión normativa de aquellos que se resisten a la diferenciación de la sociedad. El problema, traducido a términos históricos, se expresa en la pugna de fuerzas sociales que pretenden presencia o control político, en la lucha por la mantención de acuerdos económicos, en la presión por políticas sociales distributivas y sus obstáculos monetarios o en las demandas de los movimientos sociales y sus niveles de resonancia en la política. El modelo de orientación bajo estas condiciones se estructura a partir de la doble contingencia de los afectados, lo que cada uno espera respecto de sus encuentros y desencuentros, y paralelamente define la misma diferenciación de la sociedad como problema a ser resuelto ante las pretensiones de desdiferenciación que los sistemas autónomos ejercen sobre el entorno.

Entendidos de este modo, los esfuerzos de orientación sistémica contextual están dirigidos a la mantención de autonomía y coherencia en los rendimientos de la diferenciación funcional. En espacios sociales con un alto grado de funcionalización, los acoplamientos estructurales múltiples de las operaciones sistémicas permiten la coordinación sin poner en entredicho la autonomía sistémica; es decir, la coordinación actúa pragmáticamente. Por otro lado, en contextos sociales que pugnan por la desvinculación, la orientación contextual puede constituirse en herramienta empírica para producir distinciones donde los procesos desdiferenciadores dificulten la autonomía operativa de las instancias que pugnan por diferenciarse. Es decir, en general, una teoría de la orientación social pretenderá hacer ver a quienes no ven, aquello que no logran ver y que es relevante para la coordinación de las intransparencias. Como lo expresara Maturana (1982), la determinación estructural de los sistemas les impide procesar lo que escapa a sus posibilidades de observación. Mediante una teoría de la orientación contextual de sistemas sociales complejos, esta imposibilidad se probabiliza, pero no por la negación de la fuerza limitante que ejerce la estructura sistémica, sino paradojalmente por la aceptación de ella como marco de condiciones para la intervención.

\footnotetext{
${ }^{2}$ A este respecto puede verse el análisis de Miranda (2009). El autor establece las diferencias entre teorías de base normativa explícita e implícita. De especial interés, su aproximación a la distinción entre las propuestas de Luhmann y Willke.
} 
Lo anterior puede ser interpretado del siguiente modo. Cuando hablo de acoplamiento de operaciones para la coordinación pragmática de intransparencias, parto por aceptar que los modos de operación sistémica no son los mismos y que esas diferencias radican en medios simbólicamente generalizados de comunicación con diversas capacidades estructurantes, a través de los cuales es posible la auto- y heterorreferencia de los sistemas funcionales. Acoplar en este caso será desplazar y situar bajo los marcos de sentido del sistema sujeto a regulación, las distinciones orientadoras que se pretende introducir, de modo tal que el regulado comprenda desde sus propias estructuras categoriales lo que la estrategia de intervención quiere hacerle ver. Cuando esto se logra, el determinismo estructural sistémico es superado por una radicalización del mismo, lo que trae como consecuencia el reforzamiento de la propia estructura del sistema, de su clausura operacional y de su autonomía frente al entorno.

Con lo dicho, va quedando claro hacia dónde apunto con una teoría de la orientación sistémica contextual. Ante todo, ella no busca situarse en el marco del estado y responder a la pregunta acerca de cómo controlar a la sociedad. Una pretensión de este tipo, además de anacrónica, es altamente improbable frente a una complejidad social que ya no admite los panópticos de la modernidad clásica. No se trata de resituar a la política en la posición que Hobbes (2003) reclamó para ella; menos de actualizar la jerarquía hegeliana entre sociedad civil y Estado desde la cual puede leerse buena parte de la teoría política premoderna (Hegel 2006). La teoría de la orientación contextual entendida como auto- orientación de sistemas autónomos, no es una teoría del control y como tal no presupone en la sociedad ninguna estructura jerárquica que resguardar o promover. Por el contrario, en una sociedad acéntrica se regula precisamente cuando, producto de la clausura operativa, se generan asimetrías que abren el camino a la formación de jerarquías y ponen en peligro la autonomía de los sistemas involucrados. Entre jerarquía y auto- orientación existe una incompatibilidad esencial que está precisamente anclada en esta autonomía.

No existe ninguna apelación al racionalismo bajo estas premisas. La razón se interpreta por su referencia sistémica y no por su capacidad (o incapacidad) para dirigir el destino de la sociedad hacia un fin predeterminado. No hay teleología en la orientación sistémica contextual. Se orienta para que sean los mismos sistemas los que decidan cómo mantener sus estructuras o cómo transformarlas, y para que su existencia paralela en la temporalidad no se limite a la copresencia, sino que sea también coevolución. Por ello, orientar es intervenir con vistas a la coordinación pragmática de intransparencias. No propongo esta categoría para señalar el objetivo último de la orientación, sino para indicar lo que ella hace en tanto existe. La orientación contextual no controla, coordina, y coordina operaciones clausuradas de sistemas autopoiéticos intransparentes entre sí a través de una sincronización de operaciones en el momento y en el modo que tales sistemas realizan esas operaciones, es decir, coordina pragmáticamente, en el mismo acto de coordinación. En este sentido, la orientación no es una cuestión normativa, es decir, no existe un modo de operación universal frente al cual los sistemas deban alinearse para interpretar sus melodías; lo universal es su operación. Así, la tarea de una coordinación pragmática no es crear armonía, sino impedir que la atonalidad se transforme en desafinaciones que obstruyan el desarrollo de cada instrumento.

Como es posible advertir a partir de la tesis de la intransparencia de sistemas producto de la clausura operacional, la coordinación es una situación improbable que puede ser probabilizada por medio de la observación bidireccional de distinciones entre los sistemas involucrados. Sin embargo, la sola observación no es suficiente. Como afirma H. Willke (1987: 334): "El sistema intervenido entrega los criterios bajo los cuales está dispuesto a dejarse impresionar. Pero eso no basta. El sistema interventor puede no reconocer que aquellos son efectivamente los criterios en cuestión." El problema, en tanto comunicación, aparece directamente ligado al tema de la comprensión como un momento que actúa entre la observación y la operación de la orientación. Se ha comprendido cuando la reacción del 
sistema a regular se desarrolla en la dirección de las expectativas de la orientación, es decir, cuando "el que observa procesa la comprensión como un acto de su propia reproducción" (Markowitz 1987: 483), es decir, cuando se logra auto- orientación.

Planteado en estos términos, el desafío de los esfuerzos de orientación contextual será la generación de procesos de autorreflexión por medio del diseño de estrategias de intervención cuyas comunicaciones - 0 , si se quiere, distinciones - sean integradas en los sistemas intervenidos como parte de su propia circularidad basal. Sin este rasgo, la orientación no deviene reflexiva y las estrategias de intervención podrán afectar gravemente los ciclos reproductivos de los sistemas que alcanzan. Esto se expresará en dos consecuencias. La primera, una crisis funcional y estructural de ellos (desintegración de una familia, por ejemplo, o destrucción de la vida democrática por intervenciones militares); algo que se puede denominar genéricamente crisis de complejidad. La segunda, una reacción de clausura ya no operativa del sistema, sino cognitiva, lo que afectará su heterorreferencia y con ello la posibilidad de reconocer los efectos negativos de sus rendimientos para el entorno. En ambos casos, la intervención no logra el resultado buscado y la orientación coordinada entre sistemas no tendrá lugar.

\section{Forma y comunicación: las bases de la orientación contextual}

La coordinación sistémica es improbable. Esa improbabilidad radica en la clausura operativa de los sistemas. En esta sección busco esclarecer las condiciones de esa clausura y las posibilidades de apertura cognitiva en sistemas autopoiéticos de comunicación. Para ello, la estrategia seguida es la vinculación de la teoría de la forma de George Spencer-Brown con las proposiciones de Luhmann en torno a la formación de sistemas. En segundo lugar, se pretende vincular esta teoría de la forma a la emergencia del sistema social, es decir, a la existencia de sistemas cuyo modo de operación es la comunicación.

La importancia de acceder a estos niveles de abstracción para una teoría de la orientación contextual de sistemas autopoiéticos, radica en que más allá de la necesidad de conocer el modo de funcionamiento de lo que se quiere intervenir, la praxis de la intervención también exige la operación por diferencias provistas de sentido para los sistemas intervenidos. Como se observará, la intervención es un intento por hacer que las diferencias operativas de los sistemas reconozcan como propias las diferencias que introduce la intervención. En este sentido, las propias estrategias de intervención y los marcos regulativos, deben construir - lo mismo que los sistemas- distinciones bajo forma comunicativa de lo que quieren comunicar. Ni para los sistemas ni para las intervenciones, existe otro modo de operar.

Para esclarecer estos puntos, parto con la proposición de cinco teoremas diferenciados en dos niveles de abstracción (a) que permitirán ordenar la exposición desde el nivel más abstracto de la teoría de la forma (b), el mecanismo de re-entry (c) y la emergencia del orden sistémico como orden comunicativo (d).

a) Como un ejercicio que colabora al orden de la exposición, presento cinco teoremas que en su nivel más fundamental (teorema A) se encuentran en el espacio de la teoría de la forma y en su nivel más práctico (teorema Z) se enmarcan dentro de una teoría de la comunicación. La organización asignada, así como la enumeración de las proposiciones, no pretenden establecer una esquematización jerárquica de los resultados; la cuestión se reduce enteramente a criterios expositivos, que reflejan una perspectiva de observación desde la teoría observada en sí misma, es decir, sobre sus mismas observaciones.

Teorema Z, de la comunicación

La sociedad como sistema comunicativo puede solo comunicar, pero ni consigo misma como tampoco con su entorno. Ella puede, sobre la base de la distinción 
sistema/ entorno comunicar en sí misma, sobre sí misma o sobre su entorno, pero nunca consigo misma y nunca con su entorno.

Teorema $Y$, del sistema social

En el sistema social, la distinción sistema/ entorno es visible bajo la forma de una diferenciación entre comunicación y no-comunicación, siendo el sistema comunicación y el entorno no- comunicación, pero susceptible de ella de acuerdo a las operaciones de observación que el sistema realiza sobre el entorno.

\section{Teorema $C$, de la distinción sistema/entorno}

La distinción sistema/ entorno es producto de una observación hecha por el sistema que le permite a éste distinguirse del entorno, de modo tal que el sistema se constituye como la diferencia respecto del entorno.

\section{Teorema $B$, de la observación}

La observación hecha por el sistema y que le permite constituirse como la diferencia respecto del entorno, se basa en una operación de diferenciación que se asienta sobre una distinción entre observación y operación.

\section{Teorema A, de la forma}

La operación que traza una distinción entre sistema y entorno se desprende de la distinción medio/forma, siendo esta misma distinción una forma y a la vez el medio de la forma sistema/ entorno.

De tener algún valor heurístico, estos cinco teoremas habrán de permitir deconstruirreconstruir los pasos fundamentales que deben ser seguidos para entender la lógica de funcionamiento autónomo de los sistemas a intervenir. En este intento adquieren vital importancia la teoría de la forma como sustrato basal, la cuestión de la comunicación como forma operativa de los sistemas autónomos y vehículo de intervención, la distinción sistema/entorno, el énfasis operativo del funcionamiento sistémico y la conjunción de estos elementos sobre el plano del sentido de los sistemas, sentido que no está presente explícitamente en la formulación de los teoremas, pero que se expresa como un espacio vinculante en cualquier sistema psíquico y social.

Llama la atención la enumeración de estos teoremas. Mediante ella establezco una diferenciación de dos espacios de abstracción evidentemente vinculados en tanto asumen los mismos supuestos, pero distanciados en lo referente a la especificidad de su objeto. Un primer nivel de abstracción lo constituyen los teoremas C, B y A, cuya formulación hace referencia a un plano profundo donde las proposiciones son aplicables a cualquier objeto que pueda ser considerado como sistema. En este nivel lo que se pretende es vincular las proposiciones de la teoría de la forma de Spencer- Brown con la autonomía de la operación sistémica en la perspectiva de la intervención. El segundo nivel de abstracción está dado por los teoremas $Z$ y $Y$, donde es posible representar mediante el concepto de comunicación ya no una teoría de sistemas autorreferenciales, sino una teoría de sistemas sociales autorreferenciales organizados sobre la base de las estrategias selectivas del sentido orientadas a la actualización de posibilidades tendientes a la reducción de complejidad y sobre la cuales la intervención se enfrenta directamente. De este modo, los teoremas C, B y A apuntan de manera directa a aquellos elementos conceptuales aplicables a cualquier objeto que pueda ser considerado sistema; esto se ubica en el plano de la teoría de la forma. Por su parte, los teoremas $Z$ e $Y$ se sitúan en el nivel de los sistemas sociales (interacción, organización, sistema funcional), cuya particularidad, en conjunto con los sistemas psíquicos, es, como ya lo he expresado, su constitución como comunicación en el sentido.

b) Si se inicia por los teoremas C, B y A, es preciso partir por el concepto de forma como 
categoría fundamental de la descripción sistémica. George Spencer-Brown es quien desarrolla esta noción del modo siguiente:

Construcción

Trace una distinción.

Contenido

Llámela la primera distinción.

Llame al espacio en el cual es trazada, el espacio separado o dividido por la distinción.

Llame a las partes del espacio formado por la división, los espacios, estados o contenidos distinguidos por la distinción.

(...)

Forma

Llame al espacio dividido por cualquier distinción, junto con el contenido entero del espacio, la forma de la distinción.

Llame a la forma de esta primera distinción la forma. (Spencer- Brown 1979: 3, 4)

Cuando Spencer-Brown concretiza bajo el acápite de la Construcción una especie de mandato que como tal vincula al referido con el referente, está evidenciando en aquél la más básica y fundante operación que éste puede realizar: ¡Trazar una distinción!, aquella cuestión constituye la operación necesaria que permite a quien la realiza, la separación del espacio en dos estados que son alternativamente llamados los espacios distinguidos o separados por la distinción. Tales espacios distinguidos por la distinción, estados o contenidos separados por una marca de distinción que es la primera marca que produce la primera distinción es lo que por una suerte de convención es posible reconocer como la forma. La forma de la primera distinción provocada por una marca que divide el espacio en dos estados es la forma de su propia forma, es decir, es su forma y a la vez su mismo medio, en tanto de él son extraídos los elementos sueltos que constituyen mediante un acoplamiento estricto la forma básica: en nuestro teorema A, la distinción medio/forma, sobre la cual es posible, por medio de la re-entry, reproducir la forma dentro de la forma, cosa que abordo mediante la estrategia reflexiva de actualización de la diferencia dentro de la diferencia. Los sistemas se constituyen a sí mismos mediante esta distinción entre medio y forma, que es también una forma y, a la vez, el medio de la distinción sistema/entorno, que es otra forma, desarrollada en el caso de los sistemas sociales (y también psíquicos), sobre el dominio del sentido. ${ }^{3}$

\footnotetext{
${ }^{3}$ Habermas llama al sentido así definido por Luhmann un plexo de remisiones, a partir de las cuales los sistemas pueden actualizar alternativas de operación: "Como adquisición emergente, que corresponde a la conciencia, Luhmann introduce un peculiar concepto de 'sentido'. Para ello se sirve de las descripciones fenomenológicas de Husserl para quien el significado de una expresión simbólica remite a una 'intención' subyacente; la 'intención' es frente al 'significado' el concepto más primitivo. Correspondientemente, Luhmann define prelingüísticamente el 'sentido' como un 'plexo de remisiones' de posibilidades actualizables, referido a la vivencia y la acción. En vez de sujetos capaces de conciencia tenemos, pues, sistemas que elaboran sentido o emplean sentido" (Habermas 1989: 436). Es necesario aclarar que cuando Habermas habla de la 'vivencia y la acción' lo hace no en el sentido que la hermenéutica y el propio Habermas atribuyen a estos conceptos, atribución que como sabemos esta estrechamente ligada a la figura semántica del sujeto, antes bien, su orientación es la que Luhmann le otorga: "El lenguaje de esta descripción sugiere una referencia de sistema psíquico. De allí, sin embargo, debe y puede hacerse abstracción. Husserl hacía abstracción en dirección de una teoría del sujeto trascendental. Nosotros hacemos abstracción en dirección de la validez trascendental de los sistemas personales y sociales. Es decir: conceptos como intención, referencia, expectativa, acción, vivencia denominan en la siguiente presentación elementos, o sea, estructuras que pueden adjuntarse a los sistemas tanto psíquicos como sociales" (Luhmann 1991: 80). Sobre estas premisas Luhmann puede definir el sentido como "la conjunción de un horizonte de posibilidades con oportunidades de selección. El sentido, de este modo, hace especialmente disponibles formas de selectividad para el sistema. Esto incluye la comprensión de la elección como elección. Con la ayuda del sentido, las selecciones pueden ser sometidas a supervisión, control y corrección, pues el conjunto de opciones desde las cuales la selección es realizada, es retenida y permanece visible en la selección" (Luhmann 1982: 345).
} 
La orientación contextual opera en este escenario. Debe reconocer esas formas y darse a sí misma un forma para intervenir, forma que puede no ser (y que generalmente no es) aquella con la que se presenta frente al sistema intervenido, pues ante él debe, en algún sentido, guardar las apariencias, es decir, aparecer como una distinción que invita al cambio sin ejercicios coercitivos atentatorios contra la producción de distinciones del sistema. El objetivo de la intervención es aparecer como contingencia en el entorno del sistema a regular, como alternativa dotada de sentido en el dominio de sentido del intervenido.

Bajo estas condiciones, el problema del sentido debe ser abordado. Para entender lo que éste significa para los sistemas (psíquicos y sociales) es menester la concurrencia interactiva de tres conceptos: complejidad, autorreferencia y forma (Luhmann 2007). El acto de trazar una distinción en el espacio, tiene la particularidad de separar tal espacio por medio de una marca que es un límite en el espacio. Siendo límite, el espacio dividido por la marca es un espacio de continencia perfecta, es decir, la distinción no puede contener ni más ni menos que lo distinguido por ella, no hay en ella más que sus dos estados. Así, trazar una distinción que divide el espacio por medio de una marca que se instituye como límite en la escisión de los dos estados del espacio, sitúa ante la idea del cruce de los límites. Como lo expresa Spencer-Brown (1979: 1): “Es decir, una distinción es hecha por la construcción de un límite que separa lados, de manera que un lado no pueda alcanzar al otro sin cruzar tal límite. Por ejemplo, en un espacio plano el círculo traza una distinción."

Cruzar el límite entre un lado y otro de esta distinción que es una forma, permite un acercamiento al teorema $\mathrm{C}$, de la distinción sistema/entorno que es también y en tanto distinción, una forma. Cuando el sistema se diferencia del entorno por medio de una observación que es una operación de distinción (teorema B), está a la vez trazando una diferencia entre interior y exterior, diferencia que es hecha desde el interior, es decir, desde el estado llamado sistema de la forma sistema/ entorno. Las distinciones ahí hechas, esto es, las formas que surgen de las formas, así como la misma distinción sistema/ entorno, asumen una doble orientación: respecto del valor con que a sí mismos se han denominado, es decir, respecto de su interior (autorreferencia), y respecto de lo que está más allá del límite del estado interior de la distinción, es decir, el exterior (referencia externa o heterorreferencia). Como lo indica Spencer- Brown:

Podemos notar que cada lado de la distinción trazada experimentalmente, tiene dos tipos de referencia.

La primera referencia, o referencia explícita, está dirigida al valor desde el cual el estado es marcado.

La segunda, o implícita, está dirigida a un observador externo. Es decir, es el lado desde el cual se supone será vista la distinción. (Spencer- Brown 1979: 82)

O para trasladarlo al lenguaje de Luhmann:

El entorno es el horizonte total de procesamiento de información más allá del sistema. De este modo, es una premisa interna para las operaciones constituidas dentro del sistema, cuando éste usa la diferencia entre autorreferencia y heterorreferencia (o 'interna' y 'externa') para ordenarlas. (Luhmann 1989: 22)

De este modo, la referencia hacia el valor del estado marcado por una marca de distinción, en este caso, 'sistema', constituye la autorreferencia de tal estado; mientras que su orientación hacia lo externo, 'hacia el lugar desde el cual la distinción será vista', es posible gracias a la referencia externa. Esta distinción tiene importantes consecuencias para el éxito de los procesos de orientación contextual, pues por medio de la referencia externa el sistema puede observar las distinciones que el interventor le ofrece en el 
entorno; y por medio de la auto-referencia puede procesarlas e integrarlas como distinciones del repertorio propio. El sistema y la intervención asumirán entonces ambas orientaciones como premisas para el desarrollo de sus propias operaciones de observación. Así, sin el teorema A (de la forma) o el B (de la observación) es imposible pensar el C (del sistema), puesto que en la distinción sistema/ entorno, que es una forma cuyo medio es la distinción forma/medio, es posible por una observación hecha por el sistema donde se vinculan dos operaciones constituyentes: la autorreferencialidad o tematización de la propia identidad y la referencia externa o tematización de la complejidad del entorno, del horizonte de información que está más allá del sistema. ${ }^{4}$

Adviene, en este punto, el espacio para una elucidación: si el entorno es definible como horizonte, es decir, como posibilidades en suspenso, entonces la distinción sistema/entorno es universo, pues en ella está contenido lo interior y lo exterior: lo interior, lo actualizado en el sistema al operar, y lo exterior, las remisiones indeterminadas para el sistema observante, es decir, todo cuanto puede ser, y todo cuanto puede ser es simplemente todo, menos lo que ya es. En palabras de Luhmann:

Por sistema social debe entenderse aquí una relación de sentido de acciones sociales que se remiten unas a otras y que no permiten que se las delimite por acciones de otro sistema. Si se parte de este concepto de sistema que tiene su principio constituyente en una diferenciación entre interior y exterior y se busca trascenderlo, se inquiere entonces por una unidad de referencia que ya no tiene límites. Se inquiere por el universo. (Luhmann 1973: 143)

El universo no es sistema, pues no tiene un exterior sobre el cual se asiente; su existencia no es problemática en tanto nada lo amenaza: "El universo se convierte en problema no desde el punto de vista de su ser, sino desde el punto de vista de su complejidad [es decir,] la totalidad de acontecimientos posibles" (Luhmann 1973: 144). Es aquí, finalmente, donde es posible encontrar el sentido. Este regenera y selecciona la alta complejidad del mundo disponible para la operación de los sistemas psíquicos y sociales: “El sentido - según la forma y no el contenido- es, por lo tanto, reproducción de la complejidad, una forma de reproducción que permite el asimiento puntual en donde queda colocada, pero que a la vez identifica cualquier asimiento como selección, y lo hace, si se puede decir así, responsable" (Luhmann 1991: 81). Pero el sentido no solo se juega en la regeneración-simplificación de la complejidad. Cuando Luhmann habla de 'acciones sociales que se remiten unas a otras' y que impiden la intromisión de operaciones de otros sistemas, está haciendo alusión a la cuestión de la autorreferencia. Así: "Cada intención de sentido es autorreferencial en la medida en que prevé su propia posibilidad de reactualización, por lo tanto, se retoma en su estructura de remisión como una entre muchas posibilidades de vivencias y acciones adicionales" (Luhmann 1991: 81). De esta manera, el sentido tiene la facultad de trascender los límites del sistema y otorgar sentido al universo; todo cuanto exista supone la existencia del universo y todo cuanto exista, existe dentro del universo, luego dentro del sentido, incluso la negación del

\footnotetext{
${ }^{4}$ El concepto de horizonte puede ser entendido del modo siguiente: "Todo los demás, incluyendo el mundo como un todo, es asociado con éste solo por medio de referencias, i.e. accesibles solo secuencial y selectivamente. Solo una de esas posibilidades puede ser seguida a la vez, y cada avance crea más posibilidades que pueden ser tratadas posteriormente. Esto es lo que Husserl quiere decir cuando describe al mundo como 'horizonte' de intenciones actuales" (Luhmann 1989: 17). En otro lugar: "Husserl trató de captar mediante la imagen de 'horizonte' la peculiaridad del universo del hombre, que se remite al infinito y no obstante actúa como finito." (Luhmann 1973: 144). También: "El sentido remite a un sentido posterior. La cerradura circular de esta remisión aparece en su unidad como horizonte último de todo sentido, como mundo, el cual, por consiguiente, tiene la misma inevitabilidad e innegabilidad que el sentido. Cada intento de rebasarlo con el intelecto lo simplifica. Para esto el intelecto tendría que recurrir al sentido y al mundo y, por lo tanto, ser lo que se esfuerza en no ser. Husserl describió este estado de cosas con la metáfora de 'horizontes', sin haber analizado la autorreferencia en todos los sentidos"' (Luhmann, 1991: 89).
} 
sentido es realizada desde el sentido. ${ }^{5}$ La transgresión de los límites ante la cual SpencerBrown llama la atención cuando la distinción es trazada y simultáneamente el espacio es dividido en dos estados, es pensable y posible porque el sentido subyace en su operación y se constituye en la forma del mundo. Así cuando Luhmann se refiere a la dimensión objetiva del sentido ${ }^{6}$, señala:

El punto de partida de una articulación objetiva de sentido es una primera disyunción que contrasta algo indefinido frente a otro algo asimismo indefinido. Con ello, la exploración ulterior se descompondrá en un desarrollo hacia adentro y hacia afuera, en una orientación hacia el horizonte interno y, correspondientemente, hacia el horizonte externo. Surge así la 'forma' en el sentido de posibilidad de rebasar los límites y extraer las consecuencias. (Luhmann 1991: 95)

Con esto afirmo que la sentencia hay sistemas con la que Luhmann inicia su reflexión sobre sistemas, como principio es insuficiente para dar cuenta de lo que ella misma invita a pensar, o más bien a aceptar, mediante su expresión. Ante todo, no existe una identidad, sino una diferencia, sistema/ entorno, sobre la cual se construye un orden por medio de la re-introducción de la diferencia dentro de la diferencia. Efectivamente, hay sistemas, los sistemas existen, son autorreferentes, clausurados operacionalmente, pero abiertos a la información de su entorno, es decir, con una apertura cognitiva que hace posible introducir distinciones para la orientación contextual. Sin embargo la posibilidad de la existencia de sistemas se funda en la distinción trazada por el observador y más aún, como lo indica Spencer- Brown: "La concepción de la forma descansa en el deseo de distinguir. Garantizado ese deseo, no podemos escapar a la forma, aunque podemos verlo de la manera que nos plazca"(Spencer- Brown 1979: 69). Así, la posibilidad de cualquier distinción es inseparable de la misma distinción, de las marcas utilizadas para distinguir y de la operación de observación que realiza esta distinción, como se aprecia en la siguiente figura (en rigor, cada concepto debió ser escrito sobre el otro, pues solo de ese modo puede representarse el hecho que distinción, observación y operación surjan en un mismo acto). ${ }^{7}$

Si los sistemas existen, lo hacen gracias a la operación básica contenida en cada observación operada por el observador: trazar una distinción. De esta manera, la distinción, la marca y el observador, como lo expone Spencer-Brown se constituyen unívocamente: “En esta perspectiva, una distinción trazada en cualquier espacio, es una marca que distingue el espacio. Igual e inversamente, cualquier marca en un espacio traza una distinción. Es posible advertir ahora que la primera distinción, la marca y el observador, no son solo intercambiables, sino, en la forma, idénticos" (Spencer-Brown

\footnotetext{
${ }^{5}$ Sobre el sentido, Luhmann expresa lo siguiente: "El sentido siempre remite de nuevo al sentido y nunca a algo más allá del sentido o a algo diferente. Los sistema adheridos al sentido no pueden experimentar ni actuar sin sentido; no pueden dinamitar la remisión del sentido en la cual ellos mismos están implicados ineludiblemente. Dentro de la organización autorreferencial plena de sentido del mundo se dispone de la posibilidad de la neganción, pero esta posibilidad, por su parte, solo puede ser utilizada con sentido. También las negaciones $-\mathrm{y}$ esto es lo que las hace incluibles - tienen sentido. Cualquier intento de negación de sentido presupondría, de una menera general, sentido y tendría lugar en el mundo. El sentido es pues una categoría innegable y sin diferencia. Su superación (Aufhebung) consistiría -en el más estricto de los sentidos- en la aniquilación, y eso sería asunto de una instancia externa impensable" (Luhmann 1991: 82).

${ }^{6}$ Estas dimensiones del sentido son tres: objetual, social y temporal (Luhmann 1991).

${ }^{7}$ La autocontención de estos enunciados es su característica central. Como Luhmann lo expresa: “Con el término observación queremos entender, entonces, la aplicación la aplicación de una diferencia para la designación de un lado (y no del otro), sin importar qué realidad empírica realice esta operación, siempre y cuando pueda diferenciar (es decir, ver a la vez dos lados) y describir. Con George Spencer-Brown presuponemos, entonces, que la diferenciación y la descripción forman una unidad indivisible, ya que únicamente se puede describir algo diferenciable y solo se pueden usar diferenciaciones para las descripciones" (Luhmann 1992b: 277).
} 
1979: 76).

La autopoiesis de los sistemas sociales radica en esta simultaneidad de observación, operación y distinción. ${ }^{8}$ Por medio de ellos, los elementos que conforman las cadenas estructurales de los sistemas, tienen la posibilidad de la reproducción constante de sus relaciones y de sí mismos en tanto elementos. ${ }^{9}$ Bajo estas premisas, es posible encontrar en el fondo del proceso, la noción de autonomía como origen conceptual y resultado empírico de la autopoiesis. Como lo expresa R. Stichweh (1987), los sistemas autopoiéticos son sistemas autónomos, que se distinguen por medio de propiedades adicionales: (a) la clausura operacional, (b) la auto- especificación de los elementos del sistema a través del sistema, (c) una red de procesos de producción de elementos y (c) autonomía en la demarcación de los limites del sistema. Se entiende con esto que la autonomía requiere conceptualmente de la autopoiesis para definirse. Es precisamente el ejercicio de esa condición autopoiética lo que le otorga al sistema su autonomía; condición que se logra por la clausura circular de sus elementos, donde las perturbaciones del entorno solo pueden estimular la nueva síntesis de elementos dentro del sistema, la que es realizada de acuerdo a sus propias reglas de funcionamiento (Stichweh 1990). ${ }^{10}$ Esto abre las puertas para la auto- organización del sistema, el resultado fáctico que se reintroduce constantemente dentro del sistema, lo regenera y permite a las estructuras construirse y transformarse a través de sus propias operaciones; o puesto en la retórica de Morin: "la auto- organización es una organización que organiza la organización necesaria para su propia organización" (Morin 1980: 131).

c) La operación de distinciones solo inicia con la primera distinción, pero una vez puesta en marcha, se abre un universo. Esto es lo que Spencer-Brown denomina re-entry y que constituye la operación de la diferenciación interna de sistemas, es decir, formas que surgen de las formas. En el lenguaje del autor:

\footnotetext{
${ }^{8}$ En Luhmann esto se expresa del modo siguiente: "La autopoiesis es la producción recursiva de los elementos por los elementos del sistema. La observación, siendo ella misma una operación autopoiética, aplica una distinción e indica qué lado está siendo usado como base para ulteriores operaciones (incluyendo la operación de 'cruzar' e indicar el otro lado)" (Luhmann 1995: 45).

${ }^{9}$ Conocida es la posición de F. Varela en relación a la imposibilidad de entender el concepto de autopoiesis de esta manera. Para Varela, lo esencial de la autopoiesis es definida a través del concepto de producción, y en un sentido biológico, la producción está referida a cuestiones de orden químico. Por ello, Varela afirma: "Francamente, no veo cómo la definición de autopoiesis pueda ser directamente transportada a una variedad de otras situaciones, a los sistemas sociales por ejemplo. Me parece que el tipo de relaciones que definen unidades como una firma o una conversación son mejor capturadas por operaciones distintas a las productivas" (Varela 1981: 38). En un texto más reciente Varela reconoce dos sentidos de aplicación del concepto de autopoiesis. El primero, que él rechaza, hace referencia a un uso literal del término: "Cuando la idea de una red de procesos se transforma en 'interacciones entre personas', y la membrana celular se transforma en el 'borde' de un grupo humano". El segundo sentido, aceptado por Varela, entiende el uso de la autopoiesis como continuidad, donde "se trata de tomar en serio el hecho de que la autopoiesis busca poner la autonomía del ser vivo al centro de la caracterización de la biología, y abre al mismo tiempo la posibilidad de considerar los seres vivos como dotados de capacidades interpretativas desde su mismo origen" (Varela 1994: 51). En un sentido similar se expresa D. Zolo, aunque para él la autopoiesis es un error desde su gestación. Zolo acepta que el término pueda ser aplicado en un sentido empírico como reflexividad organizativa de procesos biológicos: "Sin embargo [...] Maturana y Varela -y todavía más sus seguidores- no pretenden ni por asomo asignar este significado sobrio y específico a su teoría. Por un lado, descartan en ella toda subordinación directa o finalidad en la investigación biológica empírica; por otro lado, hacen de ella - con un lenguaje irremediablemente metafísico, si no incluso 'teológico' - la esencia de la vida individual, la condición necesaria y suficiente de la existencia física de los organismos vivos. Y partiendo de aquí se creen capaces de incluso de levantar el arduo edificio de una nueva doctrina epistemológica" (Zolo 1995: 216).

${ }^{10}$ Respecto de la clausura operacional Luhmann escribe: "Para repetir una y otra vez este punto trivial, la clausura no significa aislamiento empírico. La clausura es un mecanismo selectivo, no en el sentido de un diseño intencional, sino como logro evolutivo [de los sistemas sociales]" (Luhmann 1992c: 7).
} 


\section{Nombre}

Permita que exista una forma distinta de la forma.

Permita que la marca de distinción sea copiada fuera de la forma, dentro de otra forma.

Llame a cualquier copia de la marca, una división de la marca.

Permita que cualquier división de la marca sea llamada con el nombre de un estado marcado.

Deje que el nombre indique el estado.

Arreglo

Llame a la forma de un conjunto de divisiones consideradas una respecto de otra (es decir, considerada en la misma forma), un arreglo. (Spencer- Brown 1979: 4)

La posibilidad de construir un orden recursivo emergente y de introducir distinciones desviantes en los procesos de orientación sistémica, depende de la estructuración de distinciones sobre distinciones, esto es, que la marca de diferenciación sea transportada desde la primera distinción hacia otra, produciendo otra forma que proviene de la forma. Aquí es posible introducir el concepto de información, pues solo mediante él se permite trazar nuevas distinciones. En Luhmann, la información asume necesariamente una caracterización temporal que actualiza el uso de las estructuras. Su naturaleza es ser irrepetible: "Una información cuyo sentido se repite ya no es información; conserva su sentido en la repetición, pero pierde el valor de información." (Luhmann 1991: 87). Así Bateson (1990: 88) afirma: "La información consiste en diferencias que establecen una diferencia." ${ }^{11}$ La condición para que la información comprendida de esta manera se constituya como información efectiva dentro del sistema, es decir, información que provoque diferenciación, está contenida en el carácter autorreferencial de los sistemas, esto es, sistemas cuyas operaciones tienen la facultad comunicar sobre sí mismos para desarrollar cambios de estado al interior del sistema. ${ }^{12}$ La intervención cuenta con esto para que las distinciones que ofrece sean incorporadas como información efectiva (que produce diferencias) en los sistemas regulados. Como lo expone Luhmann:

Solo a los sistema autorreferenciales se les presenta la influencia exterior como una determinación para la autodeterminación y con ella como información: la información modifica el contexto interno de la autodeterminación sin rebasar la estructura legal con la que el sistema tiene que negociar y con todo lo que de ello se sigue. (Luhmann 1991: 87)

En rigor, la marca copiada no es transportada, sino reintroducida en la forma, de modo tal que la re-entry sea asumida como un cambio de estado del sistema o como una forma que surge de la forma, aun cuando el origen del cambio haya estado en el entorno, como en los casos de intervención. En esto radica el centro de la autorregulación: la forma que surge de la distinción introducida por la intervención, es tematizada por el sistema

\footnotetext{
${ }^{11}$ El tema de la diferencia como información es sentenciado por Bateson del modo siguiente: "Kant adujo hace mucho tiempo que este trozo de tiza contiene un millón de hechos (Tatsachen) potenciales, pero solo unos pocos de ellos se vuelven hechos genuinos, al afectar el comportamiento de entidades capaces de responder a los hechos. Yo reemplazaría las Tatsachen de Kant por las diferencias, y señalaría que el número de diferencias potenciales en esta tiza es infinito, pero muy pocas de ellas se vuelven diferencias efectivas (o sea, ítems de información) en el proceso espiritual de cualquier entidad mayor. La información consiste en diferencias que establecen una diferencia: "Si yo te llamo la atención acerca de la diferencia entre la tiza y un pedazo de queso, tú serás afectado por esa diferencia, tal vez evitando comerte la tiza, tal vez probándola para verificar mi aserto. La índole no quesística de la tiza se ha convertido en una diferencia efectiva; pero otro millón de diferencias - positivas y negativas, interiores y exteriores a la tizapermanecen latentes e inefectivas" (Bateson 1990: 88).

${ }^{12}$ Podemos apreciar un primer acercamiento al teorema Z. La autorreferencialidad en tanto se ocupa de la información efectiva, o más bien, en tanto hace efectiva la información, permite que el sistema se re-introduzca en sí mismo mediante operaciones de comunicación que le abren las perspectivas para un aumento de su propia e interna complejidad, ante un aumento de la complejidad del entorno. El sistema comunica sobre sí mismo.
} 
regulado como una distinción propia si es que la heterorreferencia ha logrado observarla y la autorreferencia ha logrado procesarla. El sistema la incluye en su repertorio y opera con ella. La autorreferencialidad deviene fundamental, sea en bajo el modo de auto-referencia basal, reflexividad o reflexión (Luhmann 1991: 441-442).

Esta operación de referencia, que es una operación del sí mismo dirigida al sí mismo, es siempre conducida por una diferenciación; la posibilidad de derivar nuevas formas de la forma se asienta en que la auto- referencia sea guiada por el 'operador' de Spencer- Brown o 'la navaja de energía transistorizada de Spencer- Brown', como la llamó von Foerster (en Keeney 1991: 35). ${ }^{13} \mathrm{~A}$ tal mecanismo de operatividad se le puede denominar, siguiendo la terminología de Bateson, la pauta que conecta. ${ }^{14}$ Cada distinción trazada sobre otra genera una secuencia de puntuación de sucesos que, en su operación, van definiendo nuevos órdenes de recursión. Todos ellos, sin embargo, han de estar asentados sobre una pauta que es una metapauta y que vincula las diferencias. En los sistemas autorreferenciales, esta metapauta la constituyen las operaciones autorreferenciales guiadas por una diferencia, cuestión que clausura operacionalemente a los sistemas y les permite, por ello, estar abiertos a la información del entorno, siendo susceptibles de orientación contextual.

Así, si se trata del sistema económico, su distinción basal, su código, es pagar/ no- pagar, código que asume la forma de los precios en el medio que es el dinero. Las subsecuentes distinciones por las cuales el sistema económico pueda puntuar los acontecimientos ante los cuales se ve enfrentado, esto es: los programas, han de estar fundados en ese código (Luhmann 1999). Del mismo modo, la intervención debe vestir las distinciones que quiere introducir con ese ropaje. Así por ejemplo, el daño ecológico producido por los rendimientos propios de las operaciones autopoiéticas del sistema económico, puede ser incorporado en él no como un posible riesgo para la salud de la población, sino como la destrucción de una fuente de ganancia. El sistema económico sentirá el daño ecológico como una pérdida monetaria, que es la única forma en que puede sentirlo. Un sistema no puede salirse de sí mismo para tematizar el entorno. Aún más, es justamente por estar clausurado operacionalmente que puede 'pensar' el entorno desde su código y que la intervención debe adaptarse a su juego. De tal modo, la autorreferencialidad guiada por la diferencia está en la base de todo sistema, es la pauta de sus pautas, una metapauta.

Cuando afirmaba en el teorema $\mathrm{C}$ que la 'distinción sistema/entorno es producto de una observación hecha por el sistema que le permite a éste diferenciarse del entorno', uno se sitúa precisamente en la pauta que conecta toda formación de sistemas y toda actualización de la distinción sistema/entorno dentro de sí misma. Puesto que es el mismo sistema el que realiza la operación de distinción, la autorreferencialidad guiada por la diferencia es plenamente visible. El mismo mecanismo opera en el camino de la coevolución de los sistemas, cuando logran diferenciarse unos de otros y al interior de ellos mismos, por medio de la renuncia a la redundancia de sus funciones, es decir, por medio de la diferenciación funcional. La reflexión asume una importancia notable en este punto, ella puede ser definida como:

un proceso a través del cual un sistema establece relaciones consigo mismo. Como un resultado (y más sugerentemente) podemos llamar a la reflexión una autotematización. La autorematización hace la unidad del sistema accesible a las partes del sistema (...) En este sentido, la reflexión es una forma de participación. Mientras que una parte ciertamente no puede ser el todo, puede tematizar el todo

\footnotetext{
${ }^{13}$ El 'operador' hace alusión al monograma utilizado por Spencer-Brown para significar el acto de trazar una distinción, una especie de ' $\mathrm{L}$ ' invertida: 'T'. La 'navaja' remite a la 'navaja de Occam', de cuyo axioma, las entidades no deben multiplicarse, se decía "cortaba los problemas 'como con una navaja'” (Keeney 1991: 35).

${ }^{14}$ En rigor, Bateson (1990: 10) la define del siguiente modo: "La pauta que conecta es una metapauta. Es una pauta de pautas. Es esa metapauta la que define esta amplia generalización: que, de hecho, son las pautas que conectan."
} 
en la medida que lo percibe como un sistema generador de significados y lo relaciona a un excluido y, por tanto, delimitado entorno. (Luhmann 1982: 327)

La reflexión como autotematización, como relación del sistema consigo mismo, y la reflexividad orientada al proceso, en este caso de observación sobre la observación o diferenciación sobre la diferenciación, posibilitan la explicitación de la pauta que conecta toda re-entry de la forma dentro de la forma. Cualquier formación de sistemas y de subsistemas dentro de sistemas que definen sus propios entornos, tiene que asumir la necesaria forma de la distinción que guía una operación de referencia del sí mismo sobre sí mismo y que permite la diferenciación funcional instituyéndola como logro evolutivo de la sociedad moderna. Se trata de una operación autorreferencial, de reflexión y reflexividad, de la cual ni siquiera la misma teoría de sistemas puede escapar pues su pretensión de universalidad se funda en esta posibilidad de autotematización, es decir, de autorreferencialidad.

d) Con lo anterior, se está ya en condiciones de enfrentar el segundo nivel de abstracción, aquél compuesto por los teoremas $Y$ y $Z$. Es posible internarse en ellos mediante el problema de la complejidad, definida a través de los conceptos de elemento y relación. Los sistemas están formados por elementos y relaciones entre elementos y entre relaciones, sin embargo, la posibilidad de vinculación de cada elemento con cada elemento a través de relaciones y de cada relación con cada relación a través de relaciones que también pueden ser elementos, tiene un umbral, y ese es el punto donde ya no es posible relacionar cada uno de los elementos; es el momento de la complejidad.

La capacidad de acoplamiento de los elementos del sistema es limitada, de ahí que cuando el sistema se diferencia de su entorno mediante una operación de distinción (teorema B), es decir, una operación, y exclama desde el sistema, 'esto es sistema y esto es entorno' (teorema C), se abre la complejidad, la imposibilidad de relacionar cada elemento al interior del sistema y cada elemento del sistema con cada elemento del entorno. Es decir, el misterio en la distinción sistema/entorno es perpetuamente conservado, pues siempre hay un mundo posible por experimentar, una nueva relación entre elementos que descubrir.

La complejidad caracteriza sistema y entorno; la gradiente de complejidad, por su parte, caracteriza la relación sistema- entorno. Efectivamente, cuando el sistema se diferencia de su entorno por sus propias operaciones, asume en ese acto la existencia de una gradiente de complejidad sistema/ entorno, donde el entorno aparece más complejo que el sistema y la función del sistema se traduce en una tematización y reducción de esa complejidad del entorno mediante el mecanismo de la selectividad que, como lo he dicho, en los sistemas psíquicos y sociales es función del sentido. Los mundos posibles del entorno son actualizados y hechos experienciables al interior del sistema. Pero no son actualizados todos a la vez, sino algunos de ellos, constituyendo la complejidad estructurada del sistema, el más bajo nivel de complejidad de la gradiente de complejidad sistema/ entorno.

Al respecto, es posible distinguir una gradiente de complejidad sistema/entorno operacionalizada en cuatro dimensiones que surgen de la interacción de dos variables. Esto se puede representar en el cuadro siguiente (Luhmann 1971: 301):

\begin{tabular}{llll}
\hline & & Sistema & Entorno \\
\hline \multirow{2}{*}{ Tipo de complejidad } & Estructurada & I & III \\
& No estructurada & II & IV \\
\hline
\end{tabular}


Así, la complejidad no estructurada del entorno será el más alto nivel de complejidad de la gradiente de complejidad sistema/entorno, la absoluta indeterminación. La complejidad estructurada del entorno estará constituida por el reconocimiento que el sistema observante hace de los sistemas en el entorno; la complejidad no-estructurada del sistema la forma el medio sobre el cual el sistema desarrolla sus operaciones comunicativas y la complejidad estructurada del sistema, el más bajo nivel de complejidad, estará dado por lo actualizado en el sistema al momento de la comunicación. El desafío de la orientación contextual es hacer que aquellas consecuencias que para el sistema son de tipo IV, es decir, complejidad no-estructurada del entorno, pasen a ser parte - ciertamente no como consecuencias sino como prevención de ellas- de la complejidad estructurada del sistema, de modo tal que la desestabilización del entorno sea corregida (es decir, que se reduzca el daño ecológico, la pobreza en el caso de políticas sociales, la desestructuración de la familia en el caso de terapias familiares).

Complejidad, entonces, implica contingencia; la contingencia exige selección y la selección es riesgo. Introduzco con esto otro concepto: contingencia. La reducción de complejidad del entorno que es función del sistema, no es posible sin la selección de la indeterminación de posibilidades del entorno, o de los sistemas en el entorno del sistema observante. Tal selección sobre posibilidades que, a pesar de la selección realizada, siguen siendo posibles, es lo que define un hecho como contingente: lo que no es necesario pero tampoco imposible (Luhmann 1992a; Graevenitz/Marquard 1998; Marquard 2003).

Si en el sistema social la distinción sistema/ entorno puede ser expresada mediante una distinción entre comunicación y no-comunicación, donde el sistema (social) es lo comunicativo y el entorno lo no-comunicativo, pero comunicable en cuanto la reducción de complejidad se realiza vía comunicación (teorema Y), entonces, en tales condiciones, el sistema social no podrá hacer otra cosa que comunicar en sí mismo o desde sí mismo sobre el entorno, para hacer que lo no-comunicativo, la improbabilidad de la indeterminación contenida en la complejidad inasible del entorno, sea comunicable en su interior, y de ese modo actualizar la posibilidad misma de la existencia del sistema y garantizar que las distinciones puestas en su entorno por la orientación contextual tienen probabilidad de ser observadas. De esta manera, la evolución social pasa a ser el escenario donde la improbabilidad se transforma en probabilidad y la orientación reconoce la temporalidad como condición inescapable que debe asumir. En este mismo sentido, el propio proceso de diferenciación funcional puede ser interpretado como la comprensión de información efectiva (Bateson) al interior del sistema social, que establece una comunicación con probabilidad de éxito gracias a la cual la sociedad crea, autopoiéticamente, sus propias estructuras.

Pero definida teóricamente, la comunicación es altamente improbable, y con ello el éxito de la intervención en tanto comunicación es también improbable. Tal improbabilidad radica básicamente en tres situaciones, a) es improbable que alter comprenda el sentido de lo que ego afirma dada la individualización de la conciencia de cada cual; b) es improbable que lo comunicado trascienda a alter y ego pues es improbable que sea atendido en un contexto espacial-temporal distinto y c) es improbable que la comunicación adopte la forma de información para el receptor aún cuando sea comprendida, es decir, es improbable que éste la retenga como premisa de comportamiento (Luhmann 1981: 137- 138; también 1991).

La importancia de la superación de estas condiciones de improbabilidad se asienta en el hecho que la constitución del sistema social se realiza en la comunicación. Se trata del problema de hacer probable lo improbable: es improbable el nacimiento de un sistema social si la realización de aquello que lo posibilita es dificultosa, por tanto se hace necesario determinar teóricamente cuáles son los mecanismos que transforman la 
improbabilidad de la comunicación en probabilidad. En ello, es necesario destacar, por un lado, las fases del proceso de comunicación y, por otro, la teoría de los medios simbólicos. En cuanto a lo primero:

El planteamiento actual nos dice que la información es una selección de un repertorio (conocido o desconocido) de posibilidades. Sin esta selectividad de información no se logra ningún proceso comunicativo (...) Además, alguien debe seleccionar una conducta que notifique esta información, deliberada o impremeditadamente. Lo decisivo es que la tercera selección se pueda basar en la diferenciación entre la información y su notificación [Finalmente, quien comunica] tiene que comprenderse a sí mismo como parte del mundo con sentido, en el cual la información es correcta o falsa relevantemente: la notificación es válida, puede ser entendida. (Luhmann 1991: 154)

Así, es posible hablar de selección de información, conducta de notificación (o selección de un comportamiento para entregar una información) y comprensión. De esta manera, la comunicación del sistema sobre sí mismo, mediante la forma de la autotematización, o sobre el entorno, mediante la selección, tiene que realizarse en la conjunción de estas tres fases. La selección de información es el primer paso y supone una dificultad analítica que trataré de dilucidar. Cuando el sistema comunica lo hace siempre desde sí mismo y en sí mismo, la clausura operacional de las comunicaciones recursivas y autopoiéticas, permiten encontrar información al interior de la reflexión o la reflexividad del mismo sistema, es decir, sobre la tematización de sus partes o sus procesos. Cuando la comunicación desde el sí mismo se describe sobre el entorno, la información no aparece en el entorno, puesto que el entorno no es comunicación; en el momento en que lo es, deja de ser entorno y pasa a ser sistema. Es la distinción trazada la que permite reconocer una información como tal al interior del sistema, pues el sistema social solo comunica en sí mismo y desde sí mismo.

Consecuentemente, la selección de información no es una traslación desde el entorno hacia el sistema, del mismo modo que la marca de distinción no es transportada de una forma a otra sino reintroducida dentro de ella; se trata ante todo de un acontecimiento que aparece en el sistema, el cual debe ser distinguido para ser notificado. La comunicación adquiere condición de posibilidad, se hace probable, cuando un sistema reacciona ante la información, cuando puede distinguir entre la información y el comportamiento seleccionado para entregarla.

Bajo estas premisas el éxito de la orientación contextual se probabiliza en el momento en que el sistema a intervenir logra distinguir entre la conducta de notificación adoptada por el interventor y la información que quiere ser introducida. Si a una comunicación le sigue otra, es señal que esta diferencia fue asumida como tal, y que "la comunicación anterior se entendió" (Luhmann 1991: 156), pero esto es solo posible advertir en la comunicación siguiente: si esa comunicación se mueve en la dirección que la intervención pretendió mostrar, entonces la distinción introducida fue integrada en el repertorio operativo del sistema intervenido; la regulación tuvo éxito. La comunicación, entonces, describe un proceso recursivo de autorreferencia basal, cuyo control adviene en la confirmación posible en la próxima comunicación, cuando cada uno sabe entonces que el otro sabe que él sabe lo que el otro tenía en mente.

Estas fases del proceso comunicativo son proyectables al interior del sistema social y con ello al interior de los subsistemas que incluye el sistema social. No obstante, la posibilidad de comunicación al interior de cada subsistema del sistema social, la transformación de la improbabilidad en probabilidad, depende de la utilización de los medios. En la teoría clásica de la comunicación son recurrentes los medios de difusión, que intentan trascender los límites de la interacción comunicativa de los presentes, y el lenguaje, que emplea generalizaciones simbólicas que permiten comprender la comunicación, constituyéndose a 
la vez en fundación y producto de lo social, puesto que existe en la medida que se hace posible el esfuerzo de la comunicación. Desde una teoría sistémica de la comunicación aparece un tercer tipo de medios: los medios de comunicación simbólicamente generalizados (en la línea parsoniana de los media of interchange), que "surgen en el momento en que la técnica de difusión permite sobrepasar los límites de la interacción entre los presentes y programar informaciones para un número desconocido de sujetos ausentes y situaciones que no se conocen todavía con exactitud"(Luhmann 1991: 140). Por esto, el medio simbólico generalizado requiere de la escritura y cataliza, con ella, un proceso de diferenciación de sistemas funcionales específicos autorreferenciales que, en conjunto, posibilitan la constitución del sistema autopoiético: la comunicación improbable se regulariza en el sistema. El entorno complejo es reducido a la comunicación intrasistémica; la gradiente de complejidad sistema/ entorno se especifica en el proceso de reducción de complejidad que realiza el sistema mediante la selectividad del sentido. La contingencia de la actividad social, es decir, su indeterminación, no es eliminada, solo suspendida, pues la comunicación puede continuamente actualizar las posibilidades no adoptadas en una selección determinada mediante la vinculación diferenciadora entre información y conducta comunicativa, las cuales, en tanto son esperables, permiten la estabilización de expectativas de conducta y, con ello, la formación de estructuras que otorgan al sistema una estabilidad relativa en relación al entorno.

Esta invariabilidad relativa del sistema frente a su entorno, conduce nuevamente a la noción de autopoiesis como autorreproducción y autorreflexividad del sistema y a la necesidad de operación coordinada de los sistemas parciales. La complejidad indeterminada e indeterminable que hace de la comunicación constituyente un acto altamente improbable, deviene, vía comunicación del sistema sobre el entorno, comunicación que contrarresta contingencia sin eliminarla, en constitución de sistema: la comunicación se probabiliza sin que aquello no seleccionado se pierda como posibilidad futura.

Con los elementos entregados en los puntos anteriores he reducido a sus elementos fundantes la proposición contenida en lo que designé el teorema Z. Si los sistemas de la sociedad son definidos como sistemas sociales, ellos deben asumir una forma específica de operación; tal es la comunicación, el modo en que la sociedad se produce y reproduce autopoiéticamente. La observación del mundo no puede desarrollarse sino asumiendo esta premisa y lo que de ella se derive es consecuencia de su propia operación, operación que tiene lugar siempre y sin excepción en el sistema y desde él: la sociedad siempre comunica en sí misma y desde sí misma.

La diferencia entre información y conducta de notificación probabiliza la comunicación al interior de la sociedad e inquiere la confirmación de la información entregada: una comunicación sigue a otra, ello admite la comprensión. Pero el entorno no es comunicación, por ello la sociedad está imposibilitada de comunicar con él, sin embargo es susceptible de comunicación por parte del sistema; es decir: "La sociedad no puede comunicar con, sino solo sobre su entorno, de acuerdo a su capacidad para procesar información"(Luhmann 1989: 117). Así, el sistema aunque no comunica con el entorno, sí puede comunicar sobre él, y en él encuentra, a lo más, datos, con ello la selectividad de las distinciones de orientación puede tener lugar.

La información adquiere significatividad al interior del sistema, nuevamente. Fuera del sistema no hay comunicación, ésta se juega siempre dentro, siempre al interior de los límites, siempre en el espacio operacionalmente clausurado, recursivamente producido y auto- referencialmente ordenado de los sistemas. Quienquiera que observe fuera de este marco condicionante, se sitúa también fuera de la comunicación y al intentar observar o intervenir no lo hará; los sistemas no pueden abandonarse, pues no pueden desdoblarse y estar aquí y allá al mismo tiempo, ser alter y ego a la vez. No es posible la comunicación del sistema consigo mismo, pues este no puede aparecer dos veces en el proceso de 
comunicación, aquello supondría una identidad sistema-entorno y no una diferencia sistema/entorno, y es precisamente por esta diferencia que el sistema puede comunicar en sí mismo desde sí mismo, sobre sí mismo o sobre su entorno.

La diferencia es la marca que marca la diferencia: esto es sistema, eso es entorno. La observación es hecha por el sistema en una operación de observación que traza la distinción sistema/ entorno, así esta distinción es real y nadie puede desprenderse de ella al operar: distinción, marca, observación no son solo términos intercambiables, sino idénticos (como lo exponía Spencer- Brown). La distinción sistema/ entorno otorga forma al espacio, lo divide en dos estados; su medio es la distinción fundamental entre forma y medio. Sobre ella el sistema se constituye paradójicamente como la diferencia respecto del entorno y se permite re-introducir la forma dentro de la forma mediante la reflexividad de una auto- observación auto-referencial. Los sistemas se complejizan y diferencian; los medios en su interior se decantan; con limpieza aparece el dinero, el amor, la verdad, el poder, y la comunicación en el sistema social se traslada desde la improbabilidad a la probabilidad; las formas que surgen de las formas renuncian a la redundancia y se especifican funcionalmente. Con ello el sistema se ve obligado a hacer una permanente auto- observación, pues solo existe a través de ella; se re-introduce en sí mismo y genera auto- descripciones que le permiten comunicar sobre sí mismo: el estado en el sistema político, la justicia en el sistema jurídico, Dios en la religión, la acción para el sistema social. La comunicación en tanto recursiva, constituye este orden emergente; la posibilidad de realidad está contenida en su operación, es decir, está contenida en la sociedad, pues la sociedad como sistema comunicativo puede solo y nada más que comunicar. Si los intentos regulatorios no logran captar estas particularidades, sus probabilidades de éxito son nulas.

\section{Premisas de la orientación contextual}

Desde el punto de vista de la teoría de sistemas sociales autorreferenciales, la intervención de la realidad social está necesariamente asociada a una consideración de carácter dual respecto de los sistemas susceptibles de intervención. Esta condición dual de aproximación es instituida por las características de los propios sistemas y conduce a su revisión sobre la base de dos niveles distintos de análisis y las interrelaciones que ellos desarrollan entre sí y respecto del entorno. Tales son las instancias del código y los programas.

La operación de cada sistema funcional se asienta en el esquema del código binario. Cualquier comunicación efectiva, es decir, que tenga consecuencias (comunicativas) al interior de la sociedad depende de las posibilidades que las operaciones del código del sistema específico entreguen al funcionamiento de tal sistema. Los códigos se constituyen como construcciones totalizadoras que integran en un lado u otro de la distinción que producen todo cuanto cae bajo su dominio; excluyen una tercera posibilidad. Por esto, toda combinación contenida en ellos es contingente (ni necesaria aunque tampoco imposible), pero únicamente válida en el espacio de operación sistémica que el mismo código define y en el cual le es imperativo actuar como criterio de selección de información mediante su comunicación sobre el entorno.

En el código se describe la clausura operacional de los sistemas. Tal clausura se desarrolla en torno al código, lo que posibilita la auto-reproducción (autopoiesis) de los elementos y relaciones que caracterizan a un sistema específico funcionalmente diferenciado. Esta condición de clausura es requisito de la apertura del sistema para observar el entorno desde sí mismo, o a hacer comunicable lo que no es comunicación pero sí es susceptible de ella.

Por su parte, los programas, como resultados de la recursividad del código, permiten la apertura de los sistemas al entorno. Por medio de ellos el código de un sistema puede 
establecer dependencias recíprocas con otro sistema, cuestión trascendente en una sociedad diferenciada que requiere y promueve la integración e interdependencia funcional para su operación. En palabras de Luhmann:

A nivel del código un sistema se diferencia por medio de un esquema binario. Al mismo tiempo, se establece a sí mismo en este nivel como un sistema cerrado (...) Los programas, sin embargo, son condiciones dadas para el desarrollo de selecciones. Por un lado, ellos posibilitan una operationalización de los requerimientos que un sistema funcional debe satisfacer, y por otro, los hace permanecer variables debido a esto. En el nivel de los programas, un sistema puede cambiar estructuras sin perder su identidad determinada por el código. (Luhmann 1989: 45)

Adviene con esto una primera cuestión relevante para comenzar a tratar con el problema de la intervención sistémica de sistemas sociales. Premisa número uno: los sistemas están clausurados en términos de sus operaciones (códigos), pero abiertos a la información del entorno (programas), y están abiertos por estar cerrados. Esto conduce, nuevamente, a la proposición de una distinción al interior del sistema, aquella entre autorreferencia y referencia externa. Al afirmar la clausura operacional de los sistemas, uno se vuelca a la teoría de la autopoiesis, donde elementos y relaciones son producto del propio funcionamiento sistémico, funcionamiento que, como he descrito, no puede asir la complejidad total, constituyéndose mediante un orden recursivo y autológico. Pero los sistemas también requieren de su entorno; se distinguen como sistemas al diferenciarse de él y desde ese momento están siempre abiertos a la tematización de su complejidad. El sistema requiere de su referencia externa para reducir su complejidad captando la información desde el entorno e introduciéndola al sistema como comunicación.

Aquí introduzco otro principio. Premisa número dos: cualquier intervención sistémica no puede interferir las operaciones básicas del sistema a regular; si lo hace, destruye su autopoiesis, por tanto, destruye el sistema. Lo anterior conduce a considerar la cuestión de la intervención como únicamente factible no a nivel de los códigos sistémicos que constituyen su absoluta recursividad basal (¿cómo intervenir el sistema económico para que deje de funcionar sobre el código pagar/ no- pagar sin a la vez destruirlo?), sino a nivel de los programas traducidos en rendimientos sistémicos que esos códigos generan. Gracias a los rendimientos es como los sistemas se vinculan; por los programas un sistema se abre. La intervención tiene que apuntar en esa dimensión. En este sentido, la intervención de la realidad social debe ser en extremo cuidadosa respecto del objeto y la naturaleza de la propia intervención. Una intervención directa sobre los códigos basales del sistema puede provocar su destrucción o una abierta desestabilización de sus prestaciones sociales. Por ello, desde una perspectiva sistémica el foco de la intervención debe estar asociado a los programas que esos sistemas desarrollan a partir de los códigos, programas que vinculan el sistema a otros sistemas y al entorno y que, en definitiva, son la dimensión visible de las operaciones recursivas (cerradas, autopoiéticas) basales.

Un tercer tema es de vital importancia para que la intervención de la realidad social desde una perspectiva sistémica tenga éxito. Premisa número tres: la intervención externa debe ser procesada por el sistema que es objeto de ella. Los sistemas son intransparentes uno respecto del otro, es decir, la operación de uno no puede ser recreada por la operación del otro, pues la operación se basa en los códigos y son los códigos los que dan identidad a los sistemas. Este es un dilema que la intervención social sistémica debe salvar haciendo que el propio sistema afectado reconozca en sus distinciones aquello que la intervención pretende hacerle ver. Es decir, se trata de que el cambio introducido no aparezca como tal, que no aparezca como un elemento externo, ajeno al sistema al cual está dirigido. El papel de la intervención, en este sentido, está en hacer que el propio sistema que quiera ser intervenido procese tal cambio como necesario para seguir operando, como necesario 
para su propia subsistencia. El concepto de resonancia hace referencia a esto último (Luhmann 1989). Las distinciones introducidas por la orientación contextual en el entorno del sistema buscan producir autorregulación, por ello solo tendrán éxito cuando lo que indican logre llamar la atención del sistema, cuando en su interior provoquen resonancia, es decir, en el momento en que su significado se coordine con los significados internos.

Siendo el modo de operación específico de la sociedad la comunicación, asumiendo también que a ella le es imposible comunicar con su entorno, que el entorno no es sistema, luego no es comunicación y que la sociedad comunica en sí misma y desde sí misma, entonces la posibilidad de tematización de la intervención es nada más que una posibilidad comunicativa que se da dentro del sistema, siempre y cuando los efectos de las distinciones de la orientación contextual provoquen estímulos dentro de los rangos de percepción del sistema al que la comunicación se dirige. En esto adquiere gran importancia la observación de un sistema por otro, es decir, la observación de segundo orden. Los sistemas están estructuralmente determinados, solo ven lo que pueden ver. Con la observación de segundo orden es posible ver lo que otros sistemas no pueden ver, esto es, observar a un sistema como observador: '“Como observador' quiere decir: en vista a la manera de cómo observa. Y eso a su vez quiere decir, con vista a la diferencia que utiliza para la designación de un lado (y no del otro). O en la terminología de SpencerBrown: en vista a la forma en la cual basa su observación"(Luhmann 1992b: 277- 278).

Con la observación de segundo orden, la escasa resonancia que para los sistemas sociales sus rendimientos puedan tener sobre el resto de la sociedad, que por escasa solo constituye ruido -y como indica Teubner (1995: 177), ningún orden se logra a partir del ruido-puede incorporarse comunicativamente como alta resonancia al interior de subsistemas específicos. En ese momento los problemas generados en la sociedad como un todo pasan a ser reales, aparecen como comunicación en la sociedad y en los sistemas que los provocan, y ello establece un primer paso fundamental para intentar resolverlo.

Pero el problema subsiste: ¿cómo superar la intransparencia sistémica y producir resonancia? Los movimientos sociales protestan, elevan sus demandas a la política para que ella intente regulaciones en la economía o en los sistemas acoplados a la técnica. La política responde creando ministerios, gobiernos locales, estableciendo planes de regulación urbana, abriendo canales de información a la opinión pública. El sistema jurídico produce sus programas, legitimando una institucionalidad para el resguardo de expectativas normativas. En suma, se trata de estrategias de generación de contingencia. De este modo, como ya anticipé, una intervención sistémica orientada a producir resonancia en torno a problemas sociales debe intentar poner el tema en la perspectiva de los programas de los sistemas involucrados, es decir, tales problemas deben aparecer a los sistemas de manera tal que ellos tematicen el sentido de la comunicación de acuerdo a su repertorio conocido. La estrategia interventora debe introducir incertidumbre: generar distinciones artificiales en el entorno del sistema se pretende regular, distinciones que éste pueda reconocer en sus propias distinciones. No se trata de hacerlas sus distinciones (cuestión imposible), sino de hacerlas aparecer en sus distinciones, para que el sistema mismo llegue a la conclusión que la intervención busca. La cuestión se centra en aumentar la complejidad del sistema ante un aumento de la complejidad del entorno (requisite variety -Ashby), para que éste, sobre sus propias distinciones, es decir, sin interferir en su autopoiesis, reelabore sus rendimientos. Para lograr esto, se requiere una metódica de intervención. Esto es lo que muestro en la sección siguiente.

\section{Modelo de la orientación sistémica contextual}

Lo que en esta sección expongo es el escenario general en el cual el itinerario de la intervención define la forma que adopta la orientación sistémica contextual como 
coordinación pragmática de intransparencias sistémicas. ${ }^{15}$ El modelo propuesto a continuación es el esquema general del proceso de intervención:

Figura 1: Modelo de orientación sistémica contextual

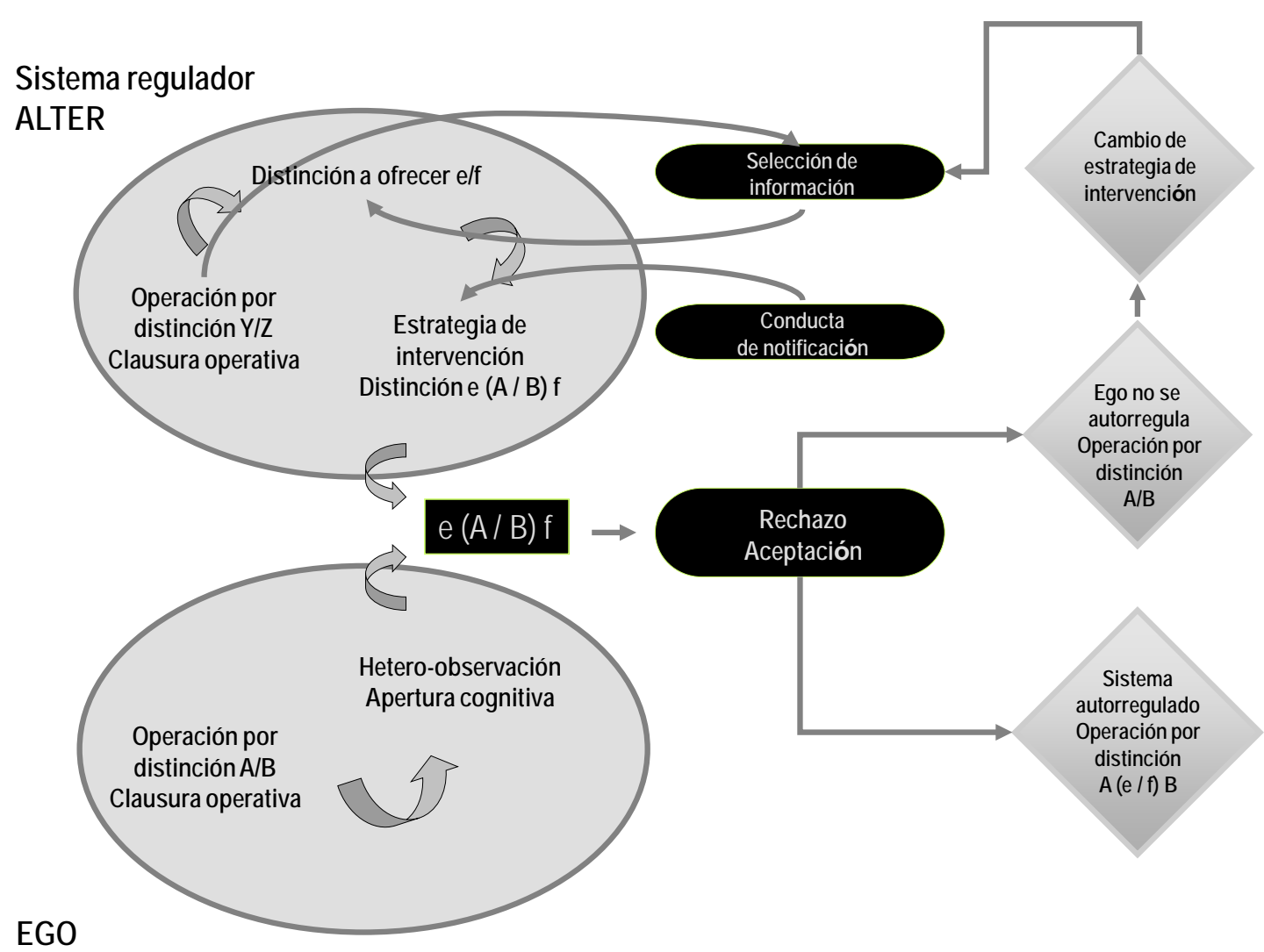

Sistema a regular

Como punto de partida, utilizo los conceptos de alter y ego para especificar la relación entre sistema interventor y sistema intervenido. Para el primero reservo el concepto de alter; para el segundo el de ego, pues solo desde el sistema que es objeto de intervención puede definirse si ésta tuvo o no éxito, es decir, solo la comunicación que sigue al acto de intervención puede determinar si las operaciones del sistema a regular se orientan en la dirección que la intervención esperaba.

Si he definido la orientación contextual como una motivación de autorregulación en el sistema intervenido y no como un ejercicio de control para el manejo heterónomo de los sistemas, entonces es necesario comenzar por responder a la pregunta acerca de cuándo intervenir.

Para una orientación contextual, la intervención es justificada básicamente ante dos situaciones. La primera de ellas es el momento en que las externalidades de la operación autónoma de ego producen desdiferenciaciones en los sistemas en el entorno, es decir, cuando ego coloniza los espacios de sentido de alter y dificulta la reproducción de su

\footnotetext{
${ }^{15}$ Una reconstrucción reciente de este modelo con alto detalle puede apreciarse en Madrigal (2009). La autora distingue entre la forma del proceso y la observación del interventor. En el primer caso observa siete momentos: visualización, diagnóstico contextual, co-diagnóstico, selección del qué, selección del cómo, relaciones intersistémicas, coconstrucción de estrategia de intervención e implementación. En el segundo caso el problema se describe desde una observación de segundo orden.
} 
autopoiesis. Un ejemplo de esto son los casos de corrupción mediante redes de estratificación y reciprocidad, las que a través de operaciones informales intervienen los procedimientos formales de las instituciones de la diferenciación funcional. Con ello permiten el acceso a rendimientos sistémicos de inclusión por vías no procedimentales (ver Mascareño 2010a, 2011a).

Un segundo flujo de acciones cuyas consecuencias pueden activar una regulación de segundo orden, es cuando las operaciones clausuradas de ego producen efectos desestabilizantes para el entorno, sin que ello necesariamente signifique riesgo de desdiferenciación. La regulación del daño ecológico producido por los rendimientos sistémicos de la economía es un ejemplo claro de este tipo de situaciones. Si los sistemas hacen lo que hacen sin necesitar más, es decir, si la clausura les impide observar más allá de lo que observan, entonces hay una alta probabilidad para que los rendimientos de un sistema se transformen en obstáculo a la operación de otros o en un peligro para su funcionamiento. Cuando la economía produce, no pretende provocar daño ecológico, pero lo hace, y si lo hace es necesario introducir autorregulaciones.

Cuando se presenta alguna de estas dos situaciones, alter puede decidir intervenir la fuente de su riesgo. De cualquier modo, el alter que interviene puede no ser el que es objeto del proceso de desdiferenciación o de las consecuencias negativas de los obstáculos para el despliegue de sus operaciones. Cuando la economía daña al medio ambiente, nadie puede esperar que el medio ambiente reaccione e intervenga la economía, aunque de algún modo lo haga entregando menos recursos de los que ofrecería sin mediar el daño, o obligando, por ejemplo, a agricultores a invertir más dinero en fertilizantes para obtener un nivel de cosecha aceptable. Del mismo modo, generalmente no es el sistema jurídico el que reacciona ante presiones políticas en contextos autoritarios. Sí lo hace en cambio - puesto que tiene mayores herramientas (parlamento, opinión pública) - en contextos democráticos. Las voces de protesta ante la desdiferenciación de política y sistema jurídico surgen generalmente desde el propio sistema político, sea por medio de corrientes de gobierno con pretensiones democráticas o por corrientes de oposición que operan sin darse la forma de partidos políticos.

Sea cual sea el nombre del alter que interviene debe, en primer lugar, saber por qué interviene, es decir, conocer qué es lo que quiere evitar o producir, cuál es la dirección en que quiere orientar al sistema intervenido. En este sentido, le cabe a las ciencias sociales un papel central. Cualquier intervención de carácter social debe estar acompañada de conocimiento acerca de la sociedad. La invitación a la autorregulación en el contexto de sistemas autónomos operando, requiere de un profundo conocimiento del modo en que trabajan los sistemas en una sociedad diferenciada. Teniendo este conocimiento, la posibilidad de intervenir con éxito no está garantizada, pero la probabilidad de su impacto positivo aumenta.

Con todo, dada una de las dos situaciones (o ambas) ante las cuales puede activarse una regulación, alter decide intervenir. Tanto ego como alter operan por medio de distinciones que constituyen sus formas de acción en relación a sí mismos y al entorno (autorreferencia y heterorreferencia). En el esquema, alter opera por la distinción $\mathrm{Y} / \mathrm{Z}, \mathrm{y}$ ego, por la distinción A/B. Habiendo decidido intervenir, alter construirá una distinción a ser introducida en el entorno de ego, la distinción e/f, su selección de información. Puesto que ego opera por la distinción $A / B$, la distinción e/ $f$ que alter quiere introducir debe ser revestida del modo de operar $\mathrm{A} / \mathrm{B}$, de forma tal que ego la reconozca como una información con sentido y la procese como parte de su complejidad estructurada. Lo que alter desarrolla como estrategia de intervención es, finalmente, una distinción del tipo $\mathrm{e}(\mathrm{A}) /(\mathrm{B}) \mathrm{f}$, y esta es la conducta de notificación cuyos efectos aparecen en el entorno de ego. 
En un lenguaje concreto y utilizando el ejemplo del daño ecológico, esto puede ser entendido del modo siguiente. La forma de trazar distinciones de la economía es a través del dinero, es decir, ego opera en el medio simbólico del dinero (distinciones A/B). Lo que busca alter (el sistema regulador), por ejemplo, el sistema político, es el fin de tal daño, representado en la distinción e/f, tal es la selección de información que la política quiere transmitir a la economía. Dada la clausura de los códigos, alter debe saber que ego, el sistema económico, no comprenderá otro lenguaje que no sea el del dinero, por ello debe vestir su intención regulativa con la distinción A/B y exponer el daño ecológico a la economía como un problema de costos a mediano y largo plazo. Es decir, alter debe mostrar a ego que el daño ecológico significará una menor sustentabilidad del medio ambiente para la producción, lo que provocará un mayor número de regulaciones (no contextuales) jurídicas para la actividad industrial y consecuentemente un aumento de los costos de producción. Esto es lo que aparece bajo la forma e(A)/ (B)f en el entorno de ego.

Por medio de la heteroobservación ego debe ser capaz de reconocer que esta distinción opera bajo el prisma de su propio código. Si lo hace, la incorporará en su repertorio de operación y su modo de funcionamiento se orientará en la dirección e/f. Ego habrá comprendido y, desde la perspectiva de alter, habrá cambiado el estado original A/ B por la distinción $\mathrm{A}(\mathrm{e}) /(\mathrm{f}) \mathrm{B}$, es decir, el sentido buscado por la intervención. Desde la perspectiva de ego, sin embargo, el funcionamiento seguirá siendo A/B. Aquí radica la razón principal por la cual llamo a la orientación contextual una coordinación pragmática de intransparencias. Si la distinción e/ f se presenta sola, ego no la incorporará a su modo de operar. Para ego, la distinción e/f no es observable porque alter es para él intransparente. Esta distinción solo adquiere sentido cuando es puesta bajo su propio prisma de funcionamiento, y aún así, ego la incorporará solamente porque aparece en su dominio semántico, siendo para él irrelevante lo que alter pretenda con ella. Para seguir con el ejemplo, alter no ha introducido en ego una preocupación por el medio ambiente o una conciencia ecológica en sentido absoluto; lo que ha logrado es que la economía reduzca el daño ecológico porque los costos de tal daño los debe asumir la propia economía en un futuro próximo. Es decir, lo que alter ha logrado, en definitiva, es una coordinación pragmática: ego hizo lo que alter pretendía que hiciera, sin que mediara consenso o convencimiento en base a las razones de alter.

Si por problemas de falta de información o por un mal diseño de la estrategia de intervención, ego no comprende la distinción que alter le sitúa en su entorno, entonces ego no desarrolla autorregulación y su operación se mantiene en la distinción A/B. Las industrias no invierten en tecnología no contaminante, no se desarrollan métodos para reciclar los desechos, los empresarios no invierten en imagen pública para autodescribirse bajo una racionalidad ecológica. Cuando esto sucede, los procesos de heteroobservación de alter captan la incapacidad de la estrategia adoptada en el momento en que la conducta de ego no se orienta en el sentido de la intervención (en nuestro ejemplo, la producción de operaciones económicas tendientes a reducir el daño ecológico) y determinan su cambio por medio de la selección de otra distinción a ser introducida en el entorno de ego. Con ello, la intervención se reintroduce en sí misma y recrea su ciclo. O termina como tal hasta nuevo aviso.

Bajo tales condiciones, debe quedar plenamente claro por qué he insistido a lo largo de estas páginas en que la orientación contextual no es una estrategia para el control sistémico, sino para la coordinación de sistemas autónomos. Con referencia a las organizaciones, M. Arnold lo formula del modo siguiente:

La capacidad estratégica de un agente de cambio proviene de su condición de observador en un plano de segundo orden. Sus acciones consisten en incrementar la variedad organizacional interna gatillando sucesos que impulsen a generar posibilidades no consideradas o anteriormente negadas. Gatillar implica estimular niveles de complejidad y autoorganización para aprovechar mejor sus condiciones 
de autorreferencialidad. Con tal objeto irritan, con distinciones, los esquemas de distinciones que subyacen a las comunicaciones organizacionales exponiéndolos y colocándolos en cuestión de tal manera que la organización percibe en su propia pantalla perturbaciones, ambigüedades, decepciones, desviaciones e inconsistencias que pueden, o no, desencadenar modificaciones estructurales en direcciones previstas. (Arnold 2008: 103)

La orientación contextual respeta ante todo la autopoiesis de los sistemas que interviene y no pretende establecer con ellos ningún tipo de vínculo heterónomo. Para una intervención clásica es fácil definir una acción e imponerla en los sistemas del entorno. La política puede definir planes de seguridad pública para acabar con el delito; o los movimientos sociales pueden proponer amplias transformaciones estructurales a través de la esfera pública; o las organizaciones solidarias pueden exigir moralmente la responsabilidad de los empresarios en relación con la pobreza. La acción es directa y probablemente efectiva mientras dura, pero cuando el tema pierde actualidad, los acontecimientos siguen su curso: el delito continúa porque tiene causas distintas a la baja represión, las transformaciones estructurales quedan en el olvido cuando la esfera pública se fascina con éxitos deportivos o con bodas reales, y los empresarios pueden continuar con faltas laborales después de sus aportes a instituciones de beneficencia. La intervención clásica es momentánea y no introduce cambios de estado en los regulados. Con la orientación contextual son los mismos intervenidos los que tienen la posibilidad de optar por una alternativa distinta a la delincuencia, de impulsar reformas estructurales en coordinación con los afectados, o de introducir condiciones equitativas en el plano laboral y no pseudo- compensaciones eventuales y esporádicas. Y todo ello sin que exista ningún alter que les obligue a hacerlo.

\section{La ética de la orientación sistémica contextual}

La orientación sistémica contextual es una alternativa a la deriva estructural de la evolución de sistemas y a la planificación centralizada de la operación sistémica. La primera se resigna fatalistamente a lo que la clausura operativa de cada instancia ordene; la segunda intenta operáticamente un control racional y finalista de la clausura operativa de cada uno de los sistemas involucrados. La primera es insuficiente para evitar que los riesgos del proceso de diferenciación sistémica se transformen en peligros inmanejables para los afectados; la segunda es en sí misma un riesgo pues dadas las condiciones de clausura operativa, cualquier intento racional de planificación genera más externalidades negativas que los resultados positivos buscados. En palabras de $\mathrm{H}$. Willke:

Si esta posibilidad de una influencia calculada no existiera, habrían solo dos posibilidades: evolución natural o desdiferenciación regresiva. De hecho, después de las profundas desilusiones del pensamiento planificador, varias propuestas se dirigen hacia esas alternativas: 'Para sobrevivir basta la evolución' (Luhmann 1984). ¿Pero basta la evolución para la sobrevivencia de sistemas sociales como las sociedades desarrolladas? ¿Quién podría creer hoy aún en eso? La confianza en la simple evolución ha sido sacudida de muchas maneras. La cuota de fracturas, riesgos ocultos e inexorabilidad de la pura evolución es demasiado alta. Por otro lado, la desdiferenciación practicada en sociedades socialistas desarrolladas muestra resultados que hacen de ese modelo cualquier cosa menos atractivo. ¿Qué hacer entonces? ¡Desarrollar una nueva opción! Más arriba, he abordado esa opción brevemente bajo la palabra clave orientación contextual [Kontextsteuerung]. Presupuesto de cada orientación es la posibilidad de un efecto calculado en otros sistemas. La plausibilidad de cada opción alternativa depende de que, por una parte, se evita la desdiferenciación (y con ello la amenaza de la autonomía de los sistemas funcionales), y por otra parte se constata que las intervenciones, a pesar de todo, son posibles. (Willke 1993: 128-129) 
En un mundo de sistemas diferenciados, las intervenciones son posibles en tanto se desarrollen de manera contextual; en tanto se reconozca la diferencia radical que existe en las lógicas involucradas, así como la diferencia radical entre los individuos participantes de los procesos de orientación. Una orientación sistémica contextual excluye condicionamientos sustantivos unívocos, precisamente porque en las formas de operación sistémica no hay univocidad sustantiva. Por ello, en sus fundamentos las estrategias de orientación contextual sistémica operan del siguiente modo (Mascareño 2006):

- Se activan frente a un llamado u opción de ego, los afectados.

- Presuponen el principio de la clausura operativa de todos los involucrados, lo que indica que no hay instrucción directa posible de ego a través de alter.

- Proponen una oferta de orientación o regulación que puede ser aceptada o rechazada por ego.

- Es ego quien decide acerca del sometimiento a la orientación o regulación.

- La orientación o regulación opera por acoplamiento estructural o mutua interferencia de ciclos comunicativos.

- En ambos casos la autonomía de ego prevalece ante las pretensiones de alter.

- Si la oferta de orientación o regulación es rechazada no hay criterios últimos para forzar el vínculo.

Bajo premisas teóricas distintas, T. Matus (2002) ha desarrollado el concepto de intervención polifónica para dar cuenta de la complejidad de los procesos de intervención en sociedades modernas. El sofisticado y altamente elaborado modelo de Matus invita a poner la mirada en cuatro dimensiones centrales: las transformaciones sociales generales, la teoría social empleada, los fundamentos epistemológicos implícitos y las perspectivas éticas y valóricas involucradas en la intervención. Tal como he expuesto las premisas de una teoría de la orientación sistémica contextual en estas páginas, ellas parecen satisfacer (casi) todos los requisitos de una intervención polifónica: comienza en el reconocimiento de las transformaciones sociales generales (diferenciación funcional sistémica de la sociedad moderna), emplea un enfoque teórico determinado (teoría de sistemas sociales) y despliega sus fundamentos epistemológicos (teoría de la forma, teoría de lo social como comunicación). Poco ha sido dicho hasta ahora de las dimensiones éticas o valóricas de una teoría de la orientación sistémica contextual, probablemente porque una teoría de este tipo no se estructura sobre un presupuesto normativo emancipatorio (justicia, solidaridad, racionalidad, naturaleza humana) que quiera ser desplegado por medio de la teoría o por medio de la praxis de intervención, sino que se estructura sobre un análisis teórico que arranca de la contingencia del mundo, no de la defensa de su unidad. Si existe algún horizonte normativo para una intervención sistémica contextual, este es evitar la eliminación de la contingencia del mundo, es decir, evitar que el mundo se transforme en un mundo necesario o que alguna expectativa del mundo sea declarada como imposible. La intervención sistémica contextual es una defensa de las múltiples posibilidades que el mundo propone a los individuos, por ello busca coherencia sin eliminar autonomía.

Los paralelos entre una intervención polifónica y una intervención contextual son, sin embargo, varios. Tanto una como otra se orientan a contextos complejos, ambas evitan un ejercicio directo de intervención, en ambas se exige una comprensión social multivariada del espacio de intervención, ambas se orientan a una traducción de lenguajes distintos, ambas tienen por tanto una función que en lenguaje hegeliano de Matus se denomina de mediación, un rol coordinador se diría en lenguaje sistémico - aunque como se advertirá, esta no es solo una diferencia terminológica. Más allá de las variaciones de lenguaje, la forma en que Matus describe tal rol, se acerca (quizás peligrosamente para la autora) al modo sistémico de entender la orientación contextual descrita más arriba: "Para poder llevar a buen término una tarea de interpretación, el trabajador social debe considerar la distancia y diferencia de fines existentes entre los intereses de las personas atendidas y los de las instituciones que ofrecen los servicios. Le corresponde, por tanto, 
una fuerte tarea de traducción de un lenguaje a otro, haciendo ver las posibles formas de compatibilización factibles y eficientes" (Matus 2002: 70). Se requiere traducción solo cuando la constelación de intervención se expresa en lenguajes distintos, es decir, para indicarlo menos metafóricamente, cuando las instancias involucradas se estructuran sobre su propia clausura operativa. Pero para que la traducción tenga probabilidades de éxito, Matus también debe presuponer la apertura cognitiva de esas instancias. Esto es lo que reconoce a través del concepto de mediación: "La función mediadora del trabajo social debe contener la posibilidad de recuperar la unidad de lo razonable dejando escuchar sus múltiples voces" (Matus 2002: 67).

Es precisamente en este último punto donde se puede apreciar la gran y quizás única diferencia entre una intervención polifónica y una intervención contextual. La intervención polifónica busca encontrar la unidad de lo razonable entre los distintos lenguajes, busca menos una traducción entre idiomas diversos que un lenguaje común en el cual todos los involucrados puedan entenderse. Para encontrar esa lingua universalis, Matus recurre a lo único que, desde su matriz interpretativa, se puede recurrir en un mundo postmetafísico: a principios. En directa relación con la propuesta habermasiana de la ética del discurso, Matus propone la justicia y la solidaridad como fundamentos éticos de una intervención polifónica. El primero se conecta con la igualdad de derechos individuales, el segundo con la empatía y preocupación por la comunidad. Pero las cosas no quedan ahí. Indica la autora: "es la ética del discurso la que explica por qué ambos principios provienen de una misma raíz moral que es la vulnerabilidad necesitada de compensación de seres que solo pueden individuarse por vía de socialización, de suerte que la moral no puede proteger lo uno sin lo otro" (Matus 2002: 95). La ética del discurso como mecanismo procedimental sería en última instancia la encargada de la articulación discursiva en las constelaciones de intervención. Es decir, lo que Habermas (1971) llama los principios ilocucionarios de la ética del discurso - dejarse convencer por el mejor argumento, no restringir temas a priori, orientación a la comprensión mutua y veracidad en las formulaciones expresadases el mecanismo que permitiría encontrar la unidad de lo razonable que la intervención polifónica busca.

Una intervención contextual, o más precisamente, la orientación sistémica contextual, tiene menos pretensiones. No espera que los involucrados estén inicialmente de acuerdo en adoptar la ética del discurso como procedimiento de resolución de conflictos para solucionar conflictos que seguramente se desarrollaron porque los involucrados no cumplieron con lo que la ética del discurso prescribe. Para una orientación contextual la alternativa no es hacer ahora bien lo que antes se hizo mal. Su comprensión de la clausura operativa es radical, no se la minimiza o relativiza bajo el presupuesto de que al menos se aceptarían los criterios de una ética del discurso cuando existan conflictos producidos por el uso de discursos y lenguajes diferentes. Si en alguna ética se basa la orientación contextual, ella puede ser denominada como ética de la contingencia (Mascareño 2006, 2011b). Esto supone el reconocimiento de la plena autonomía de lenguajes en las constelaciones de intervención y, por tanto, de la imposibilidad de una visión común de los sistemas involucrados (psíquicos o sociales). Por ello, una orientación contextual no opera privilegiadamente por vía discursiva ni argumentativa. Cada instancia tiene buenos argumentos para hacer lo que hace y si no los tiene, las consecuencias de su operación no son menos fácticas. En ello radica el reconocimiento de la contingencia: las razones pueden ser unas, otras, pueden faltar o pueden no querer ser conocidas o formuladas porque basta operar fácticamente para obtener los resultados esperados (discriminación, abusos de poder, golpes militares). O también las justificaciones pueden seguir parámetros no occidentales de legitimación para los que los pilares de una ética discursiva carecen de sentido. En un mundo contingente no hay medida última de unidad de lo razonable.

Pero a la vez, porque cada instancia está clausurada en su lenguaje, está también 
cognitivamente abierta a la información del entorno. Esta es la ventana abierta que aprovecha la orientación contextual para activar su praxis. Si se basa en una ética de la contingencia, entonces no esperará un convencimiento argumentativo del otro, sino que intentará seducir pretendiendo hacer ver a la fuente de riesgo que lo que la intervención busca es lo mejor para ella. Con ello no hay ninguna orientación a la unidad de las operaciones de los involucrados en una constelación de intervención, pues si la fuente acepta la comunicación es porque le ha parecido pertinente a la reproducción de su red de operaciones clausuradas, no porque una racionalidad de justicia o solidaridad haya desdiferenciado su clausura y se haya vuelto más humana: una empresa que certifica el carácter ecológico de sus productos aumenta sus ventas, una organización con responsabilidad social hacia sus empleados incrementa su productividad, un gobierno que invierte en la superación de la pobreza recibe mayores preferencias políticas. Es cierto que por tratarse de un mundo contingente, una orientación contextual no tiene garantía de éxito ni fundamento para volver a insistir cuando las cosas no resultan como se esperaba. Pero puesto que no hay una exigencia final orientada al entendimiento como la contenida en la ética del discurso, sino solo la posibilidad de una coordinación pragmática de la diferencia, volver a intentarlo sigue siendo una opción, tanto como desistir, sea porque falta motivación, porque entretanto el problema ya no es relevante o porque por efecto de la propia contingencia se juzga solucionado.

De cualquier modo, puesto que la orientación contextual se basa en una ética de la contingencia, la alternativa polifónica puede permanecer como posibilidad contingente. Si ella contribuye a la coordinación de la complejidad sistémica de un mundo diferenciado como plausiblemente lo muestra Matus, entonces pasa la prueba pragmática que la orientación contextual presupone. En tal caso, la intervención polifónica puede ser vista como un componente de la orientación contextual. La situación inversa, sin embargo, no es posible. Para una orientación contextual basada en una ética de la contingencia, el entendimiento es un anexo lujoso de la coordinación pragmática de intransparencias, prescindible cuando la satisfacción de intereses particulares alcanza para resolver los problemas generales. Cuando los abismos de la diferenciación e individuación se ensanchan, el mundo se vuelve no solo polifónico sino también atonal, cromático, de modo tal que no hay armonía posible que una las voces. En un mundo tal solo parece posible preocuparse de la pragmática del ritmo. RM

\section{Bibliografía}

Arnold, M. (2008): Las organizaciones desde la teoría de sistemas sociopoiéticos. Cinta de Moebio, (32), 90- 108.

Bateson, G. (1990). Espíritu y naturaleza. Buenos Aires: Amorrortú.

Graevenitz, G. y Marquard, O. (1998). Kontingenz. München: Wilhelm Fink Verlag.

Habermas, J. (1971). Theorie der Gesellschaft oder Sozialtechnologie? Eine Auseinandersetzung mit Niklas Luhmann. En J. Habermas y N. Luhmann, Theorie der Gesellschaft oder Sozialtechnologie (pp. 142- 290). Frankfurt a. M.: Suhrkamp.

Habermas, J. (1989). El discurso filosófico de la modernidad. Buenos Aires: Taurus.

Hegel, G.W.F. (2006). Filosofía del espíritu. Buenos Aires: Editorial Claridad.

Hobbes, T. (2003). Leviatán. Buenos Aires: Losada.

Keeney, B. (1991). Estética del cambio. Barcelona: Paidós Ibérica. 
Luhmann, Niklas (1971). Systemtheoretische Argumentationen. Eine Entgegnung auf Jürgen Habermas. En J. Habermas y N. Luhmann, Theorie der Gesellschaft oder Sozialtechnologie (pp. 291-405). Frankfurt a. M.: Suhrkamp.

Luhmann, N. (1973). Ilustración sociológica y otros ensayos. Buenos Aires: Sur.

Luhmann, N. (1981). La improbabilidad de la comunicación. Revista Internacional de Ciencias Sociales, 33(1), 137- 138.

Luhmann, N. (1982). The Differentiation of Society. New York: Columbia University Press.

Luhmann, N. (1989). Ecological Communication. Chicago: The University of Chicago Press.

Luhmann, N. (1991). Sistemas sociales. México D.F.: Universidad Iberoamericana, Alianza Editorial.

Luhmann, N. (1992a). Kontingenz als Eigenwert der modernen Gesellschaft. En N. Luhmann, Beobachtungen der Moderne (93-128). Opladen: Westdeutscher Verlag.

Luhmann, N. (1992b). Sociología del riesgo. México D.F.: Universidad Iberoamericana/ Universidad de Guadalajara.

Luhmann, N. (1992c). Operational closure and structural coupling: the differentiation of the legal system. Cardozo Law Review, 13(5), 7- 36.

Luhmann, N. (1995). La autopoiesis de los sistemas sociales. Zona Abierta. La teoría de los sistemas autorreferenciales, 70/71, 21- 51.

Luhmann , N. (1999). Die Wirtschaft der Gesellschaft. Frankfurt a. M.: Suhrkamp.

Luhmann, N. (2007). Sociedad de la sociedad. México D.F.: Herder, Iberoamericana.

Madrigal, J. (2009). Del control a la coordinación de la oferta. Propuesta para una intervención social funcionalista sistémica. Tesis Mg. Trabajo Social. Santiago: Universidad Católica de Chile.

Marquard, O. (2003). Zukunft braucht Herkunft. Stuttgart: Reclam.

Markowitz, J. (1987). Konstellationsformen psychischer Selbstreferenz Vorstudien zu einem Begriff der Partizipation. En D. Baeker, J. Markowitz, R. Stichweh, H. Tyrell, H. Willke (eds.), Theorie als Passion (pp. 482- 518). Frankfurt a. M.: Suhrkamp.

Mascareño, A. (2006). Ethics of Contingency Beyond the Praxis of Reflexive Law. Soziale Systeme, 12(2), 274- 293.

Mascareño, A. (2010a). Diferenciación y contingencia en América Latina. Santiago: Ediciones Universidad Alberto Hurtado.

Mascareño, A. (2010b). Soziologische Erkenntnisblockaden und der lateinamerikanische Weg der Moderne. Leviathan, (26), 336- 356.

Mascareño, A. (2011a). Entre la diferenciación y los individuos. Derechos fundamentales y las redes de la infamia. Estudios Públicos (próxima aparición). 
Mascareño, A. (2011b). The Ethics of the Financial Crisis. En P. Kjaer, G. Teubner y A. Febbrajo (eds.): Crisis in Constitutional Perspective: The Dark Side of Functional Differentiation (pp. 333- 353). Oxford: Hart Publishing.

Maturana, H. (1982). Erkennen: Die Organisation und Verkörperung von Wirklichkeit. Ausgewählte Arbeiten zur biologischen Epistemologie. Braunschweig/Wiesbaden: Friedr. Vieweg \& Sohn.

Matus, T. (2002). Propuestas contemporáneas en trabajo social. Hacia una intervención polifónica. Buenos Aires: Espacio Editorial.

Miranda, P. (2009). La verdad y lo político. Democracia y ley natural. Persona y Sociedad, 23(2), 51- 70.

Morin, E. (1980). Self and autos. En M. Zeleny (ed.), Autopoiesis. A theory of living organization (pp. 128-142). New York: North Holland.

Spencer- Brown, G. (1979). Laws of Form. New York: E.P. Dutton.

Stichweh, R. (1987). Die Autopoiesis der Wissenschaft. En D. Baeker, J. Markowitz, R. Stichweh, H. Tyrell, H. Willke (eds.), Theorie als Passion (pp. 447-481). Frankfurt a. M.: Suhrkamp.

Stichweh, R. (1990). Self- organization and autopoiesis in the development of modern science. En W. Krohn, G. Küppers y H. Nowotny (eds.), Selforganisation. Portrait of a scientific revolution (pp. 195-207). Dordrecht: Kluwer Academic Publishers.

Teubner, G. (1993): Law as an autopoietic system. Cambridge, Massachussets: Blackwell Publishers.

Teubner, G. (1995). 'Y Dios se echó a reír...' Indeterminación, autorreferencia y paradoja en el Derecho. Zona Abierta. La teoría de los sistemas autorreferenciales, 70/71, 159- 202.

Varela, F. (1981). Describing the logic of the living. The adecuacy and limitations of the idea of autopoiesis. En M. Zeleny (ed.), Autopoiesis. A theory of living organization (pp. 36- 64). New York: North Holland.

Varela, F. (1994). Prefacio de Francisco J. Varela García. En H. Maturana y F. Varela, De máquinas y seres vivos. Autopoiesis: la organización de lo vivo (pp. 34-61). Santiago de Chile: Editorial Universitaria.

Willke, H. (1987). Strategien der Intervention in autonome Systeme. En D. Baeker, J. Markowitz, R. Stichweh, H. Tyrell, H. Willke (eds.), Theorie als Passion (pp. 333361). Frankfurt a. M.: Suhrkamp.

Willke, H. (1993). Systemtheorie entwickelter Gesellschaften. Dynamik una Riskanz moderner gesellschaftlicher Selbstorganisation. München: Juventa Verlag.

Zeleny, M. (1980). Autopoiesis: a paradigm lost? En M. Zeleny (ed.), Autopoiesis, dissipative structures, and spontaneous social orders (pp. 3-44). Washington: American Association for the Advancement of Science.

Zolo, D. (1995). Autopoiesis: crítica de un paradigma posmoderno. Zona Abierta. La teoría de los sistemas autorreferenciales, 70/71, 203- 262. 
Sobre el autor

Aldo Mascareño obtuvo su grado de Doctor en Sociología en la Universidad de Bielefeld, Alemania. Actualmente es profesor investigador en la Escuela de Gobierno de la Universidad Adolfo Ibáñez. Entre sus últimas publicaciones más destacadas se encuentran, (2010) Diferenciación y contingencia en América Latina (Santiago: Ediciones Universidad Alberto Hurtado) y (2011) The Ethics of the Financial Crisis (En P. Kjaer, G. Teubner y A. Febbrajo (eds.): Crisis in Constitutional Perspective: The Dark Side of Functional Differentiation (pp. 333- 353). Oxford: Hart)

aldo.mascareno@uai.cl

\section{Contacto}

Escuela de Gobierno

Universidad Adolfo Ibáñez

Diagonal Las Torres 2640, Peñalolén

Santiago de Chile

Recibido: Julio/2011

Aceptado: Agosto/2011

Artículo disponible en: http:// www.facso.uchile.cl/publicaciones/mad/25/mascareno01.pdf 